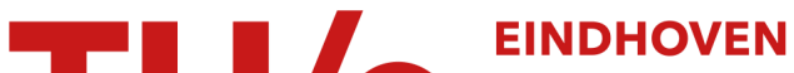 \\ UNIVERSITY OF \\ TECHNOLOGY
}

\section{Modeling and control of compressor flow instabilities}

Citation for published version (APA):

Willems, F. P. T. (1996). Modeling and control of compressor flow instabilities. (DCT rapporten; Vol. 1996.151).

Technische Universiteit Eindhoven.

Document status and date:

Published: 01/01/1996

\section{Document Version:}

Publisher's PDF, also known as Version of Record (includes final page, issue and volume numbers)

\section{Please check the document version of this publication:}

- A submitted manuscript is the version of the article upon submission and before peer-review. There can be important differences between the submitted version and the official published version of record. People interested in the research are advised to contact the author for the final version of the publication, or visit the $\mathrm{DOI}$ to the publisher's website.

- The final author version and the galley proof are versions of the publication after peer review.

- The final published version features the final layout of the paper including the volume, issue and page numbers.

Link to publication

\section{General rights}

Copyright and moral rights for the publications made accessible in the public portal are retained by the authors and/or other copyright owners and it is a condition of accessing publications that users recognise and abide by the legal requirements associated with these rights.

- Users may download and print one copy of any publication from the public portal for the purpose of private study or research.

- You may not further distribute the material or use it for any profit-making activity or commercial gain

- You may freely distribute the URL identifying the publication in the public portal.

If the publication is distributed under the terms of Article 25fa of the Dutch Copyright Act, indicated by the "Taverne" license above, please follow below link for the End User Agreement:

www.tue.nl/taverne

Take down policy

If you believe that this document breaches copyright please contact us at:

openaccess@tue.nl

providing details and we will investigate your claim. 


\title{
Modeling and control of compressor flow instabilities
}

\author{
Frank Willems
}

Report No. WFW 96.151

Advisor: Dr.ir. Bram de Jager

Eindhoven, June 13, 1997

Eindhoven University of Technology (TUE)

Faculty of Mechanical Engineering

Control Engineering Section 



\section{Abstract}

Stable operation of both axial and radial compressors is constrained by the occurence of aerodynamic flow instabilities: rotating stall and surge. Developments in the understanding of the physics behind these instabilities and ideas of how to stabilize the compressor system, have opened the door to a new era in the field of compressor control.

This study gives an overview of the current state in modeling and control of surge and rotating stall in axial and radial compressors. It summarizes different types of aerodynamic flow instabilities that can occur in these machines. Compressor performance is discussed on the basis of compressor maps and important features of these instabilities are treated. But, this work focuses on active control systems applied in experimental systems. Compressor models that are used frequently in controller designs are described and the effect of assumptions on the prediction capability of these models is discussed. Furthermore, this report deals with control concepts to guarantee stable operation and an outline is given of sensors, actuators and controllers applied in laboratory set-ups.

The main contribution of this study is the comparison of aerodynamical flow instabilities found in axial and radial compressors, of several models, and of controllers implemented on experimental set-ups. It appeared that the behavior of a compressor system subsequent to instability onset is reasonably grasped but the considered models can not describe all types of instabilities encountered. Nevertheless, the Moore-Greitzer model seems an useful starting point for further research since it describes the compressor behavior subsequent to the onset of rotating stall and surge. A better understanding of the mechanism(s) behind the onset of these instabilities may allow refinements to existing models and may give insights into new control methods. Currently, apart from a few exceptions, only complex-valued proportional feedback controllers are used. More advanced, nonlinear controllers are expected to improve the performance of the compressor system. 


\section{Contents}

$\begin{array}{ll}\text { Abstract } & \text { i }\end{array}$

1 Introduction 1

2 Rotating Stall and Surge $\quad 3$

2.1 Performance of Axial and Radial Compressors . . . . . . . . . . . . 3

2.2 Aerodynamic Flow Instabilities . . . . . . . . . . . . 5

2.2 .1 Rotating stall ..................... 7

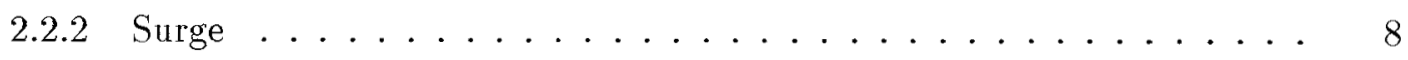

2.2.3 Rotating Stall and Surge in Radial Compressors . . . . . . . . 10

2.3 Discussion .............................. 10

3 Modeling of Compression Systems $\quad 12$

3.1 Compression System Models . . . . . . . . . . . . . . . . . . 13

3.1.1 Basic Compression System . . . . . . . . . . . . . 13

3.1.2 Greitzer Lumped Parameter Model . . . . . . . . . . . . . . . . 13

3.1.3 Control-Oriented High-Frequency Turbomachinery Model . . . . . 20

3.1.4 Botros Compression System Model . . . . . . . . . . . . . . 22

3.2 Compressor Models . . . . . . . . . . . . . . . . . . . . . . 24 
3.2 .1 Moore Model . . . . . . . . . . . . . . . . . . . . 24

3.2 .2 Moore-Greitzer model . . . . . . . . . . . . . . . 26

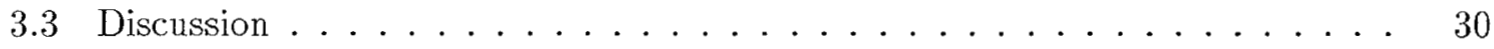

3.3 .1 Discussion of Assumptions . . . . . . . . . . . . . . . . 32

4 Active Control of Surge and Rotating Stall $\quad 34$

4.1 Stability of compression systems $\ldots \ldots \ldots \ldots \ldots \ldots$

4.2 Control of Surge and Rotating Stall . . . . . . . . . . . . 35

4.3 Active Control Systems . . . . . . . . . . . . . . . . 40

4.3 .1 Sensors and Actuators . . . . . . . . . . . . . . 40

4.3 .2 Controllers ........................ 43

5 Conclusions and Future Research 44

5.1 Modeling of Compressor Flow Dynamics . . . . . . . . . . . . . . . 46

5.2 Control of Compressor Flow . . . . . . . . . . . . . . . 47

$\begin{array}{ll}\text { References } & 49\end{array}$ 


\section{Chapter 1}

\section{Introduction}

Turbomachines are widely used for industrial and aerospace applications. Many of these applications include compression of air for use in industrial gas turbines and aircraft gas turbine engines in order to produce mechanical power at the shaft [14]. Other applications are transportation of natural gas in the petroleum industry and pressurization of gas in process and chemical industries. The performance and efficiency of these turbomachines is limited by the occurrence of instabilities. This study focuses on two types of aerodynamic flow instabilities associated with axial and radial compressors: rotating stall and surge [34]. These instabilities can lead to catastrophic failure of the system due to large mechanical or thermal forces in the blading. Therefore, suppressing these instabilities would benefit the large community of users of these turbomachines.

According to, e.g., $[17,23]$, active control of aerodynamic flow instabilities is a promising solution. This control strategy can effectively shift the surge line, i.e., the stability boundary of a compressor, to flow regimes where steady operation was impossible without control. The increased operating range will be beneficial for, e.g., off-design operation of aircraft and gas turbine engines due to disturbances and efficient (part-load) operation of serial or parallel compressor configurations. Moreover, this control strategy gives a potential for a large increase in machine performance [23].

The aim of this work is to provide an overview of the state of the art in modeling and control of surge and rotating stall in axial and radial compressors. Compared to other surveys and overviews, e.g., $[12,44,34,36,48]$, the main contribution of this study is the comparison of several models, of controllers implemented on experimental set-ups, and of aerodynamic instabilities met in axial as well as radial compressors.

This report is organized as follows. First, in Chapter 2 a brief introduction is given into the operation of axial and radial compressors and an overview is presented of the types of aerodynamic instabilities met in these compressors. Chapter 3 deals with models that describe these instabilities and their properties. The stability of compression systems and the basic idea of suppressing these instabilities by active control is illustrated in Chapter 4 . This chapter 
also provides a comparison between experimental results of several active control systems. As well, the influence of actuator and sensor choice on system performance and applied control schemes are discussed. Finally, in Chapter 5 conclusions are drawn and possible directions for future research are suggested. 


\section{Chapter 2}

\section{Rotating Stall and Surge}

A large variety of turbomachines are commonly used by fluid engineers: fans, pumps, compressors and turbines. This chapter concentrates on axial and radial compressors and starts with a brief outline of the operation principles of these machines in Section 2.1. The aerodynamic flow instabilities encountered in both compressor systems are treated in Section 2.2 and are compared with each other in Section 2.3 .

\subsection{Performance of Axial and Radial Compressors}

Four types of compressors can be distinguished [53]: reciprocating, rotary, axial, and radial compressors where rotary compressors are the least used in industry. The operating ranges of reciprocating, axial and radial compressors are shown in Fig. 2.1. Reciprocating and rotary compressors operate on the principle of decreasing the volume of the fluid. In axial and radial compressors, the pressurization of the entering fluid is accomplished by first accelerating it by the kinetic energy imparted in the rotors and then converting the kinetic energy into potential energy by decelerating the fluid in diverging channels. In an axial compressor, this is realized by flow through the diverging stator blade passages and in radial compressors by flow through the diffuser [14]. The increase in potential energy of the exiting fluid is manifested by a rise in pressure. This conversion of kinetic energy into potential energy can be explained from the Bernoulli equation [46]:

$$
\frac{p_{1}}{\rho}+\frac{U_{1}^{2}}{2}+g z_{1}=\frac{p_{2}}{\rho}+\frac{U_{2}^{2}}{2}+g z_{2}
$$

where $p$ is the pressure, $\rho$ the density of the fluid, $U$ the velocity of the fluid, and $g z$ the potential energy per unit mass. The indices 1 and 2 indicate properties before and after deceleration respectively.

This study focuses on two commonly used types of continuous flow compressors: the axial compressor where the gaseous fluid is processed in a direction parallel to the rotational axis and the radial or centrifugal compressor where the pressurized fluid leaves the compressor in a 


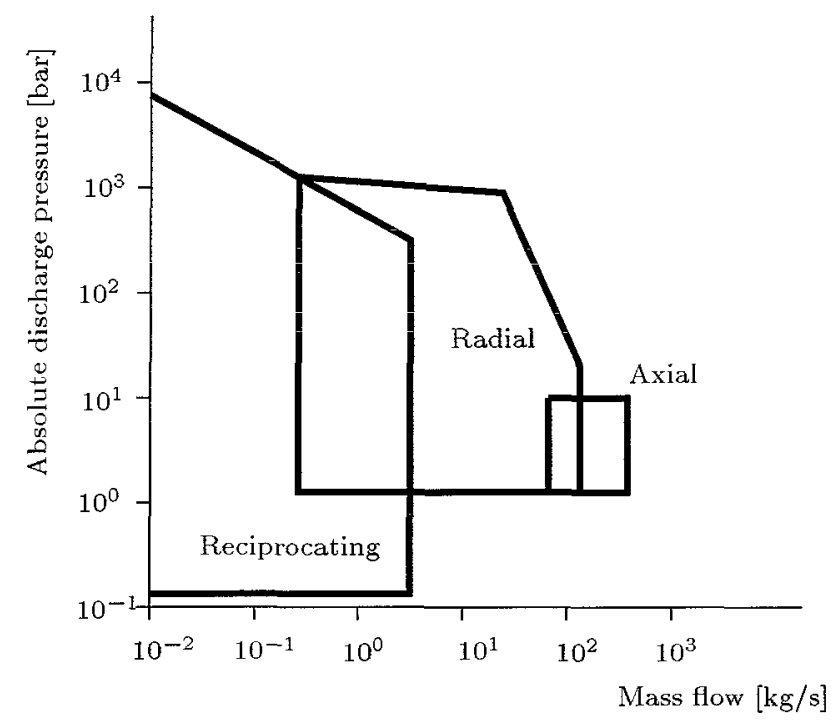

Figure 2.1: Ranges for application of reciprocating, axial, and radial compressors [53].

direction perpendicular to the rotational axis. As shown in Fig. 2.1, axial compressors are high flow machines while radial compressors are high pressure machines [21]. The performance of a compressor is often specified by curves that relate the rotational speed, pressure rise across the compressor, and mass flow through the compressor in the compressor map, as shown in Fig. 2.2. Actually, compressor manufacturers provide compressor maps in which these properties are scaled by using reference pressures and temperatures. For a detailed discussion on scaling, the interested reader is referred to [15, Chapter 1]. Steady-state operating points with constant rotational speed are indicated by speed lines (also called compressor characteristics) and the rotational speed increases in the direction of the arrow. The operating range of a compressor is bounded for high mass flow by the limited capacity of the compressor due to choked flow $[24,53]$ marked by the stonewall line while for low flow regimes the operating range is limited by aerodynamic instabilities, so-called rotating stall and surge. The stable region is demarcated by the surge line or stall line. Application of the Buckingham $\Pi$ theorem (see, e.g. $[51]$ ) learns that four dimensionless parameters are required to uniquely define the operating point of the compressor $[24,44,54]$ :

- Pressure rise $\Psi$, e.g., dimensionless total-to-static pressure rise $\frac{\Delta P}{\rho U^{2}}$ (with mean rotor speed $U$ and specific mass $\rho$ ). This ratio provides a measure of the actual work put into the fluid to the potential work available $\left(U^{2}\right)[15$, Chapter 1$]$.

- Mass flow $\phi$, e.g., dimensionless compressor mass flow $\frac{C_{x}}{U}$ (with axial flow velocity $C_{x}$ ). For an axial compressor, this mass flow determines the incidence into the first rotor and then in turn into the blade row downstream. This incidence is an important property in determining the performance of a blade row. For radial compressors, $\phi$ is often defined as $\frac{\dot{m}}{\rho_{1} U_{2} D_{2}^{2}}$ with mass flow rate $\dot{m}$, impeller outlet speed $U_{2}$, and inlet density $\rho_{1}[15$, Chapter 1]. 


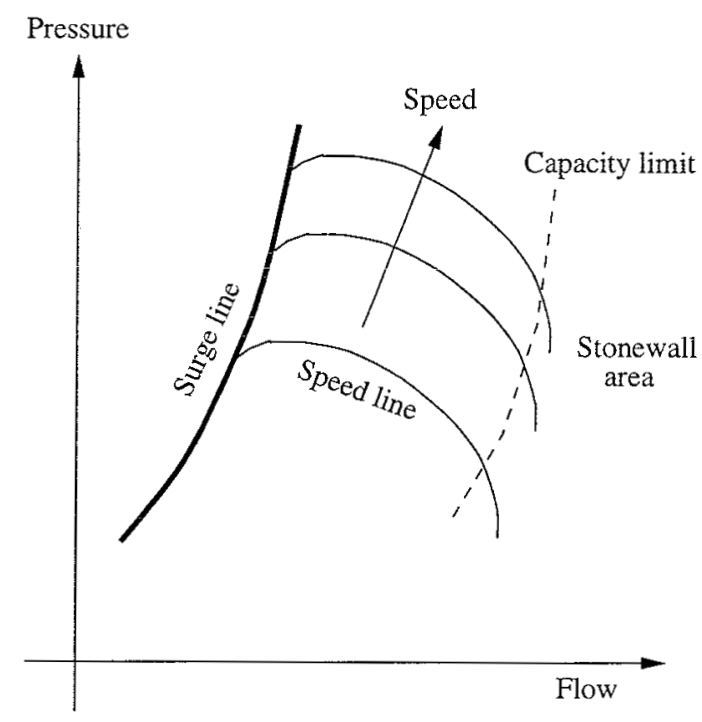

Figure 2.2: A schematic representation of a compressor map [53].

- Compressor speed $n$, e.g., dimensionless tip speed or mean rotor speed expressed in Mach number.

Additionally, the temperature rise or a related variable like the efficiency could be added. Regions of highest efficiency are located near the surge line, as shown, e.g., in Fig. 7 in [34]. In steady state, an operating point can be defined by two independent dimensionless variables because $\Psi, \phi$ and $n$ are connected via the compressor map. From Fig. 2.2, it is seen that the pair $(\Psi, n)$ does not uniquely define an operating point while $(\phi, n)$ and $(\Psi, \phi)$ do.

Some typical characteristics for axial and radial compressors are shown in Fig. 2.3. Note that the axis of these characteristics have different scales but the shapes of the curves are representative. Curves 1 and 2 would be found in radial compressors, curve 3 might be for an axial compressor, and the discontinuous curve 4 might be found for a multi-stage axial compressor. As seen in Fig 2.1, a radial compressor generally operates at higher pressure ratios in combination with lower mass flows compared to axial compressors. The steady-state operating point of a compression system is set by the intersection point of the compressor characteristic and the pressure requirements of the system characterized by the load line or throttle line. Typical system pressure requirements are depicted in Fig. 2.4.

\subsection{Aerodynamic Flow Instabilities}

Several types of instabilities can be encountered in compression systems, e.g., instabilities in systems with combustion and in ram jets. This study is restricted to aerodynamic flow instabilities in axial and radial compressors: rotating stall and surge. Aeroelastic instabilities 


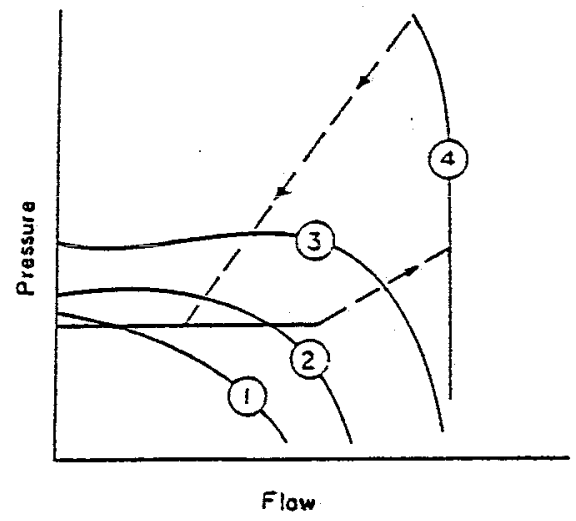

Figure 2.3: Typical compressor characteristics [34].

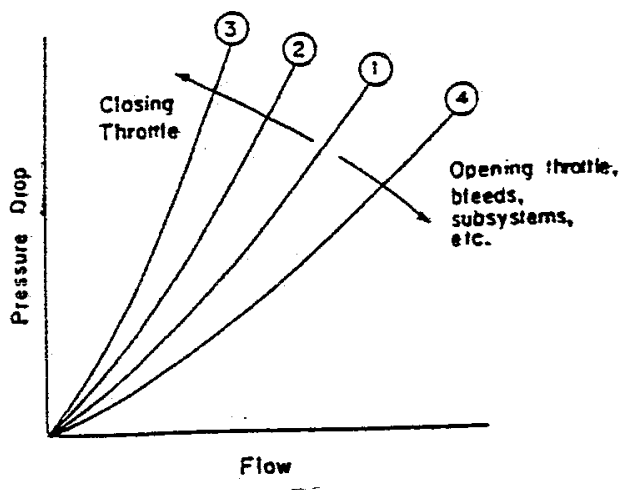

Figure 2.4: Typical system pressure requirements [34]. 
such as flutter in axial compressors also fall outside the scope of this study. The interested reader is referred to [34] for a review of instabilities in pumping systems.

Aerodynamic flow instabilities are encountered in both axial and radial compressors [29, 34], but especially in high pressure ratio radial compressors there seem to be differences. Therefore, rotating stall and surge are first discussed on a general basis in Section 2.2.1 and 2.2.2 (for surge) whereas differences for radial compressors are discussed separately in Section 2.2.3.

\subsubsection{Rotating stall}

Rotating stall is a local instability phenomenon in which one or more cells of severely stalled flow rotate around the circumference of the compressor with a constant rotational speed which is usually between 20 and $70 \%$ of the rotor speed. In this flow regime, the annulus-averaged compressor mass flow is steady in time but the mass flow has a circumferential mass deficit and, therefore, is essentially a two-dimensional phenomenon.

Experimental work of Day [18] done at two low-speed axial compressors show that stall cell development can follow different paths: (i) growth of modal perturbations and (ii) abrupt formation of finite stall cells. These stall cells are classified as short or long length scale cells referring to the size of the cell when it first forms. The growth of modal perturbations into a fully developed stall cell is consistent with the Moore-Greitzer model [50]. However, Day [17] shows that suppressing the first modal wave, which is in some cases the precursor of rotating stall $[41,55]$, does not prevent the occurence of a small length scale cell. In [34], the various types of rotating stall are divided on the basis of the size of the stalled region of the annulus height in part-span or full-span stall. A typical example of part-span stall is shown in Fig. 2.5a in which we see two regions of stalled flow at the tip. But, also examples are known of stall cells appearing at the hub [34]. Full-span stall cells cover the entire height of the annulus and can fill more than 180 degrees of the compressor annulus (Fig. 2.5b). These stall cells extend axially through the compressor whereas part-span stall can exist in only part of the compressor, even a single blade row. The full-span type of instability

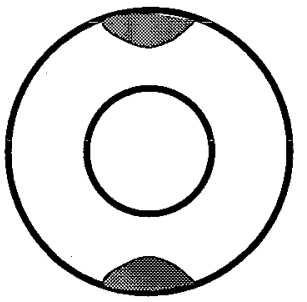

Figure 2.5: a) Part-span stall

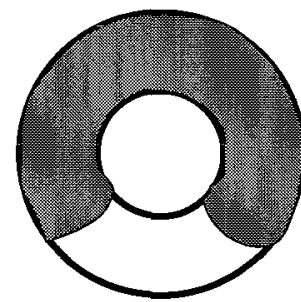

b) Full-span stall.

most commonly occurs in multi-stage compressors. Part-span stall is often seen to occur in single-stage compressors [18] and the first stage during low-speed operation of multi-stage high pressure ratio compressors [17,34]. It is seen from [15, Chapter 9] that full-span stall 
is encountered in compressors with a so-called abrupt stall compressor characteristic; this behavior depicted in Fig. 2.6 leads to a significant drop in pressure rise and mass flow. Partspan stall is more likely to occur in compressors with a progressive stall characteristic, i.e., a compressor characteristic with a small drop in pressure rise and mass flow at stall inception. However, if the compressor in part-span stall is throttled further, it may lead to full-span; the part-span cells grow radially and axially and may finally result in one cell through the whole length of the compressor. Part-span cells very often rotate at close to $50 \%$ of the rotor speed whereas full-span cells usually rotate more slowly in the range $20-40 \%$.

The accurence of rotating stall is seen in the compressor map as follows: if the operating point is forced, e.g., by a throttle valve, to mass flows just left of the stall line on a constant speed line, the operating point moves rapidly from the unstalled characteristic (1) where the mass flow is axisymmetric to a operating point (2) on the stalled characteristic with nonaxisymmetric mass flow [36], as shown in Fig. 2.6. The uncontrolled compression system

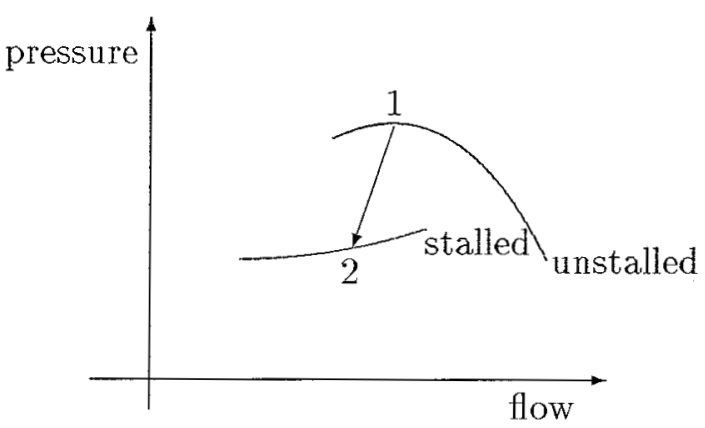

Figure 2.6: Compressor map with stalled flow characteristic [44].

will remain in point (2) if this is a stable operating point of the system. Note that annulusaveraged values of the mass flows are used in the compressor map. An example of a measured stalled characteristic can be found in $[8,16,18]$. Hysteresis effects also seems to play an important role whether rotating stall is more or less difficult to recover from [19,34]. These large hysteresis effects are commonly encountered in multi-stage compressors near design speed [34], see curve 4 in Fig. 2.3. Rotating stall induces vibratory stresses in the blading and, depending on the stalled characteristic of the compressor, there can be a large drop in performance and efficiency. Moreover, in a gas turbine engine the reduced flow rates during rotating stall can lead to undesirable thermal loads in the turbine [36].

\subsubsection{Surge}

Surge is characterized by large amplitude fluctuations of the pressure rise and unsteady but circumferentially uniform, annulus-averaged mass flow. This essentially one-dimensional phenomenon affects the compressor system as a whole and results in a limit cycle oscillation in the compressor map as depicted in Fig. 2.7. These oscillations result in a considerable loss of performance and efficiency and can lead to high blade and casing stress levels. The 
frequencies of surge oscillations are typically over an order of magnitude less than those associated with rotating stall. From experiments, see, e.g., $[40,56]$, it is known that the surge frequency is on the order of the Helmholtz frequency (for details, see Section 3.1.2) and it decreases with increasing rotational speed. This trend is confirmed by the experimental work of Greitzer [32]. Note that rotating stall frequencies are on the order of the rotor frequency but, contrary to surge frequencies, they do not depend on system parameters [34]. Depending on the amplitude of the flow and pressure fluctuations, four categories of surge can be distinguished [44]: mild surge, classic surge, modified surge and deep surge. The latter is the more prevalent type occurring at high speeds and pressure ratios [19].

Fig. 2.7 shows a typical example of a deep surge cycle which is associated with any significant flow reversal. During a deep surge cycle four phases can be distinguished (see, e.g., Fig. 8

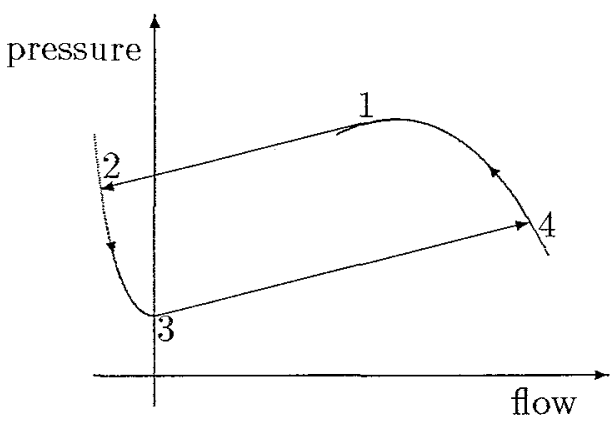

Figure 2.7: Compressor map with deep surge cycle [44].

in [29] for a radial compressor or Fig. 15 and 17 in [32] for an axial compressor): for nearly constant mass flow the relatively slow filling and emptying phases of the plenum and two rapid changes in mass flow between these phases with constant plenum pressure. Note that during the rapid decrease in mass flow the pressure falls further in case of a smaller plenum volume $[19,32]$. The filling and emptying phases are basically set by a balance between the resistance of the compressor and throttle and the mass storage capability of the volumes of connecting ducts [34]. In backward flow, the compressor operates quasi-steadily on the steady-state back flow characteristic (line segment 2-3 in Fig. 2.7) during the emptying phase. This line defines the resistance which the rotating blades offer to flow in the reversed direction [19]. The line is thought to be unique to a particular compressor and has roughly a parabolic shape. In the forward flow phase, when the plenum is filled, the compressor moves relatively slowly along its characteristic (line segment 4-1 in Fig. 2.7) [29]. The filling period is generally longer than the emptying period because in reversed flow the plenum is emptying through the throttle and the compressor. As a result, the frequency of oscillations during deep surge is normally well below the Helmholtz frequency since it is set by the plenum filling and emptying time $[29,56]$. This is in agreement with experimental results reported by Day for a low-speed multi-stage axial compressor [19]. The "squared" shape of the deep surge cycle transforms in a more elliptical shape for more mild surge types [19, 32, 44]. The mass flow fluctuations reduce significantly compared to deep surge and mass flow stays positive. 


\subsubsection{Rotating Stall and Surge in Radial Compressors}

Typical shapes of compressor characteristics found for low pressure ratio radial compressors are Curve 1 and 2 shown in Fig. 2.3. Speed lines of a high pressure ratio radial compressor are quite steep due to compressibility effects, see, e.g., Fig. 2 in [63]. Also, the margin between the surge line and stonewall line becomes increasingly narrow for increasing speed and delivery pressure. For an impression of the influence of the density of the fluid on the compressor characteristic see, e.g., Fig. 2.12 in [53].

Axial and radial compressors mostly show similar flow instabilities [34]. But, in radial compressors system instability is infuenced by the matching between elements such as the volute and diffuser [29]. This is supported by the "component-by-component" analysis in $[43,66]$ in which the influence of each element on system stability is examined. Often, the vaned diffuser is found to be the most important contributor to instability [20,34, 43,63] although this is not the general case. Wo and Bons [66], for instance, indicate the vaneless pipe diffuser as the most destabilizing element in their radial pump. For high pressure ratio radial compressors, relatively large mass flow fluctuations are encountered even in the negatively sloped region of the compressor characteristic before the onset of system instability [63]. During these fluctuations, conditions necessary for instability onset are assumed to be met [34]. This is in contrast with the results found for axial compressors where often small disturbances grow into rotating stall.

Rotating stall is believed to have little effect on compressor performance in radial compressors $[19,44]$, so analysis are generally restricted to surge in these machines. This is in agreement with experimental results $[20,43,56,63,66]$. Nonetheless, rotating stall can occur in radial compressors $[29,60]$. Fink et al. [29] even found impeller stall initiating deep surge in a high-speed single-stage radial compressor. In [54], the experimental work of Ribi and Gyarmathy is mentioned who found impeller stall in a single-stage radial compressor for lower rotor speeds (tip Mach number $M_{t} \leq 0.4$ ). In the pioneering work of Emmons et al. [22] also rotating stall occurs in the radial compressor under investigation. A brief overview of surge and rotating stall in radial compressors can be found in [54].

\subsection{Discussion}

As a rule, the aerodynamic flow instabilities occur at the top or in a point of the compressor characteristic with a certain positive slope (see [7, 17, 38, 41, 55] for axial compressors and [29, $37,56]$ for radial compressors). Linear analysis demonstrate that this stability boundary is set by the relation between the slope of the compressor characteristic, the slope of the load line, and the Greitzer stability parameter (see Section 4.1 for further details). The behavior of the compressor subsequent to instability onset is reasonably grasped. Examples of experimental studies are $[17,19,32]$ and $[29,43,63,66]$ for axial and radial compressors respectively. Rotating stall is believed to be important in low-speed axial compressors $[18,41]$, while surge occurs at relatively high speeds $[29,37,56]$. Furthermore, surge goes into rotating stall if the size of the plenum is progressively reduced [19]. Both results are in accordance with the 
theoretical and experimental work of Greitzer [31, 32, 35] (see Section 3.1.2 for details).

Rotating stall may be unrecoverable due to large stall/unstall hysteresis; e.g., opening bleed valves or decreasing the rotor speed by changing the amount of injected fuel will not restore the system to its unstalled condition [44]. Especially in aircraft gas turbine engines, this socalled "hung" stall is undesirable since it requires a full stop and restart of the engine. This hysteresis effect is commonly met in multi-stage compressors near design speed. During surge, on the other hand, the engine operates in an unstalled condition over part of the cycle, so this type of aerodynamic flow instability is more favorable for recovery [34]. Besides the effect on recovery, Greitzer concludes from simulation results (Fig. 24 in [34]) that the presence of significant stall/unstall hysteresis makes rotating stall more likely to occur; the calculated transient responses of two identical systems subsequent to identical initial conditions result in surge for the compressor characteristic without hysteresis and in rotating stall for the same characteristic with hysteresis. In [19], it is argued that relatively small mass flow fluctuations will lead to classic surge in case of small stall/unstall hysteresis. According to [34], this is not correct and moreover hysteresis is disadvantageous for the occurence of a surge cycle.

Both unstable phenomena surge and rotating stall are assumed to be related, since rotating stall can trigger surge [23,34]. This idea is confirmed by the experimental results reported for an axial compressor [17, 18, 19] and for a radial compressor [29]. Day's experiments show that a rapidly growing stall cell rotates 4 a 5 rotor revolutions around the annulus before the flow was fully reversed (deep surge). Therefore, Day concludes that any active suppression technique that delays the onset of rotating stall will also be effective in delaying surge. This idea is emphasized by the experimental results discussed in $[17,18,26]$. Experimental results of Badmus et al. [3] show the existence of a mixed surge/rotating stall mode. The relation is confirmed from the fact that rotating stall and surge are natural oscillatory modes of the compression system with surge corresponding to the zeroth order mode and rotating stall representing higher order modes $[34,55]$. This will be discussed in more detail in Chapter 3.

Unstable flow phenomena in axial compressors are generally much better understood $[29,34$, 44]. One reason might be that there has been considerably less engineering effort applied to studies of flow instabilities in radial compressors [34]. Another difficulty at arriving at a general description of radial compressor instabilities is the very wide ranges of speeds and compressor geometries and the effect of matching components [29]. However, contradictory opinions and experimental results are found in literature and it is concluded that more effort is needed for a thorough understanding of the mechanism(s) that lead to the considered aerodynamic flow instabilities. 


\title{
Chapter 3
}

\section{Modeling of Compression Systems}

\begin{abstract}
An essential step in controller design is the understanding of the physical phenomena in the system and the development of a mathematical model that describes the most important phenomena. Depending on the application, two important types of models can be distinguished for rotating stall and surge control: a control model that predicts the time development of these flow instabilities and guides the development of a controller. Consequently, this model has to be mathematically compact because active control of flow instabilities requires fast control actions (order of $1-5[\mathrm{~ms}]$ ). On the other hand, more complex simulation models are used for system dynamic analyses.
\end{abstract}

As seen in, e.g., $[2,24,25]$, the models found in literature can be classified in several ways. The classification in this study is based on the fact that the modeling of surge and rotating stall requires two different approaches [48]; surge is associated with primary axisymmetric disturbances and involves mass flow and pressure variations in the entire compression system. Therefore, the plenum and throttle have to be incorporated in the model to study this unstable phenomenon. Rotating stall, on the other hand, involves regions of stalled mass flow which rotate around the circumference of the compressor. In this flow regime, only the average mass flow and pressure rise interact with the plenum and throttle since the flow redistributes and pressure variations decay away from the compressor [18, 48]. As a result, the model has to account necessarily for the circumferential variations of flow within the compressor for this kind of instability. Hence, in this study the models are divided into models that describe the behavior of the entire compression system (Section 3.1) and models of the fluid dynamics inside the compressor (Section 3.2). Finally, the most important properties of the models discussed in this chapter are summarized and compared with each other in Section 3.3. 


\subsection{Compression System Models}

\subsubsection{Basic Compression System}

An idealized compression system is depicted in Fig. 3.1. In this idealized system, an enter-

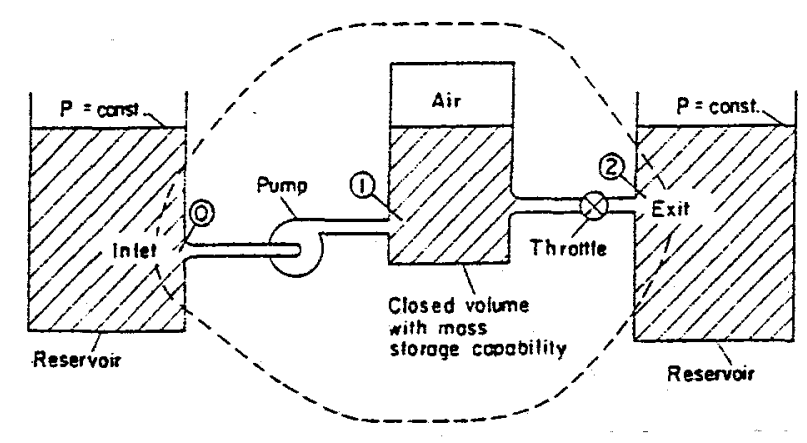

Figure 3.1: A basic compression system [34].

ing, incompressible fluid is pressurized in the compressor and is discharged in a closed tank which contains a compressible gas. This tank discharges via a throttle valve in another large reservoir. Essential elements in this system are the compressor which realizes the pressurization, the inertance of the incompressible fluid in the compressor and throttle ducts, the mass storage capacity of the system in the closed tank, and the throttle which represents the system pressure requirements, e.g., losses due to resistance in the piping or effects of subsystems, and which determines the flow rate. As the pressure of both reservoirs is chosen to be equal and all dissipative effects in the system are modeled by the throttle, the steady-state operating point of the compression system can be found at the intersection point of the compressor characteristic and the load line; the mass flow through the compressor and throttle are identical and the compressor pressure rise equals the pressure drop across the throttle. In this steady-state situation, the average net mechanical energy provided by the compressor is entirely dissipated by the throttle.

\subsubsection{Greitzer Lumped Parameter Model}

A frequently used compressor model for dynamic analysis and controller design of axial compressors is the lumped parameter compression system model [31] shown in Fig. 3.2, see, e.g., $[7,57,58]$. This fourth order model is based on the Helmholtz "organ-pipe" resonator type of compression system model introduced by Emmons et al. [22] in which the compression system is represented by two large volumes connected to each other by a duct in which the compressor works. The interconnecting duct is supposed to be small so the fluid in this duct 
can be assumed incompressible. As a result, the kinetic energy of the fluid is associated with the motion in the duct whereas the potential energy is related to the compression in the large plenum. In other words, compressibility effects are associated with the compression of the fluid in the plenum while inertia effects are lumped on the acceleration of the fluid in the compressor duct. In this lumped parameter model, the compressor is replaced by an actuator

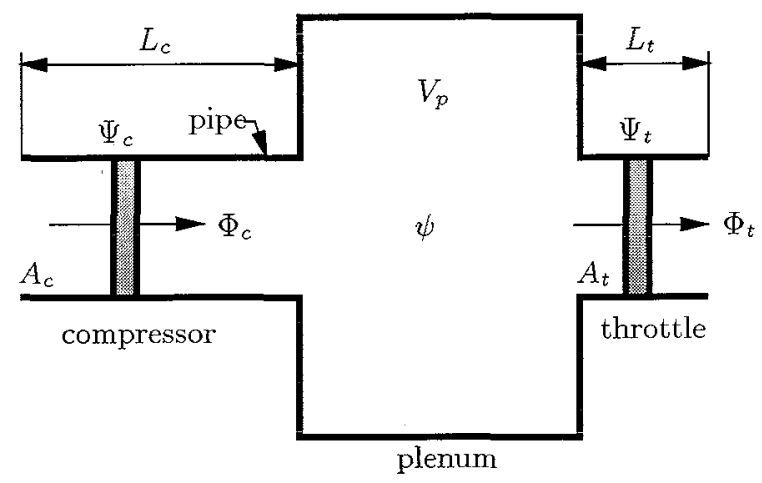

Figure 3.2: Lumped parameter compression system model [31].

disc and a pipe of length $L_{c}$ to account for the fluid dynamics in the compressor duct. This actuator disc is a representation of a blade row as a plane across which the mass flow is continuous but the total pressure and circumferential velocity can be discontinuous [34]. The equivalent duct (effective length $L_{c}$ and flow through area $A_{c}$ ) is modeled such that a given rate of change of mass flow gives the same pressure difference in the actual duct as in the model. This compressor duct is connected to a large plenum and the fluid is discharged from the plenum via a throttle in an exit duct of much smaller diameter than the plenum. The throttle is modeled in a similar way as the compressor: a combination of an actuator disk and a equivalent duct of length $L_{t}$ and flow through area $A_{t}$.

The following major assumptions are made in the lumped parameter model:

1. One-dimensional incompressible flow in the ducts. This assumption seems reasonable because the model describes systems with low inlet Mach numbers and pressure rises are assumed to be small compared to the ambient pressure.

2. Isentropic compression process in the plenum.

3. Uniform plenum pressure rise $\psi$ in the entire plenum.

4. Negligible velocity in the plenum.

5. Quasi-steady throttle behavior. A frequently encountered description of the throttle behavior is given by $[7,65]$ :

$$
\Phi_{t}=K_{t} \sqrt{\Psi_{t}}, \quad K_{t} \geq 0
$$


where $K_{t}$ is the throttle area parameter. The throttle is closed $\left(\Phi_{t}=0\right)$ if $K_{t}=0$. In [31], the following relation is used:

$$
\Psi_{t}=\left(\frac{A_{c}}{A_{t}}\right)^{2} \Phi_{t}^{2}
$$

6. Unsteady compressor response can be simulated by a first-order time lag $\tau$.

7. Influence of rotor speed variations on the system behavior is negligible. In [32], a single compressor characteristic is used and the experiments and dynamic analyses are performed for a single value of mean rotor velocity. It is noted that the compressor characteristics can collapse into a single curve if dimensionless properties in the compressor map are chosen properly, as shown in, e.g., Fig. 4 in [29].

Applying the one-dimensional momentum equation to the flow in the compressor and throttle duct and the principle of mass conservation to the plenum gives, together with the first order transient compressor response, results in a set of four coupled nonlinear differential equations. As discussed in Section 2.1, often dimensionless variables are introduced. In [31], ambient density $\rho_{a}$, mean rotor velocity $U$, and compressor duct area $A_{c}$ are combined to normalize mass flows by using $\rho_{a} U A_{c}$, pressures using $\frac{1}{2} \rho_{a} U^{2}$, and time using $1 / \omega_{H}$. This results in the following set of dimensionless equations:

$$
\begin{aligned}
\frac{d \Phi_{c}}{d t} & =B\left[\Psi_{c}-\psi\right] \\
\frac{d \Phi_{t}}{d t} & =\frac{B}{G}\left[\psi-\Psi_{t}\right] \\
\frac{d \psi}{d t} & =\frac{1}{B}\left[\Phi_{c}-\Phi_{t}\right] \\
\frac{d \Psi_{c}}{d t} & =\frac{1}{\tau}\left[\Psi_{c, s s}-\Psi_{c}\right]
\end{aligned}
$$

where $\Psi_{c, s s}$ is the dimensionless steady-state compressor pressure rise which can be determined from the measured steady-state compressor map, $\Psi_{t}$ is the dimensionless pressure drop across the throttle given by Eq.(3.1), and $\Phi_{c}$ and $\Phi_{t}$ are respectively the dimensionless mass flow through the compressor and throttle duct. The actual dimensionless compressor pressure rise is represented by $\Psi_{c}$, so modeling the unsteady compressor behavior by Eq.(3.6) has the effect of slower growing instabilities. In this compression system model, three dimensionless system parameters are introduced:

$$
B=\frac{U}{2 \omega_{H} L_{c}} \quad G=\frac{L_{t} A_{c}}{L_{c} A_{t}} \quad \tau=\frac{2 \pi R N}{U}
$$

with $R$ the compressor mean rotor radius, $N$ the number of rotor revolutions before the stall cell is fully developed, and $A_{t}$ the throttle flow through area.

The $B$-parameter (also called Greitzer stability parameter) depends on the mean rotor velocity $U$, the effective length $L_{c}$ of the equivalent compressor duct, and the Helmholtz frequency $\omega_{H}$ which is given by:

$$
\omega_{H}=a \sqrt{\frac{A_{c}}{V_{p} L_{c}}}
$$


where $a$ is the speed of sound and $V_{p}$ is the plenum volume. The $B$-parameter appears to be a quantitative measure to predict the behavior of the compression system subsequent to perturbations past the stall limit. In literature, values of $B$ between 0.25 and 2.7 are found, see, e.g., $[3,19,29,40]$. Systems with $B$ above a critical value $B_{c r i t}$ exhibit surge, whereas a value of $B$ less than $B_{\text {crit }}$ points to rotating stall. Comparison of values found in literature (0.4 [19] and 0.8 [31]) make clear that $B_{\text {crit }}$ is different for each compressor. To overcome this problem, Day [19] introduced a new dimensionless group:

$$
B_{\text {crit }}^{\prime}=B_{\text {crit }} \frac{\psi_{\text {at peak }}}{\Phi_{c, a t \text { peak }}}
$$

Then, $B_{c r i t}^{\prime}$ varies between 1.1 and 1.3 for several compressors. Further increase of the $B$ parameter beyond $B_{\text {crit }}$ will result in a change of the elliptical classic surge cycle into a more circular deep surge cycle [32]. In [32, 33, 34], Greitzer attempts to give a physical interpretation of the $B$-parameter. Following these analyses, the effect of the $B$-parameter on system behavior can be motivated if one realizes that the $B$-parameter can be written as:

$$
B=\frac{\frac{1}{2} \rho_{a} U^{2} A_{c}}{\rho_{a} \omega_{H} U L_{c} A_{c}}
$$

This parameter can be seen as the ratio of pressure and inertial forces in the compressor duct; the numerator is proportional to the magnitude of the pressure difference across the duct and represents the driving force for the acceleration of the fluid in the duct. Assuming oscillations to be sinusoidal and axial velocity oscillations to be a specified fraction of the rotor speed, the denumerator is proportional to the order of magnitude of the inertial forces in the compressor duct that arise because of local fluid accelerations. Thus, increase of $B$, for instance by a decrease in $L_{c}$, will result in relatively smaller inertial forces compared to the driving force due to the pressure difference. Accordingly, larger mass flow variations can be expected due to the increased driving force, so there will be a general trend towards surge rather than rotating stall.

The $G$-parameter can be interpreted as a measure for the importance of the inertia of the fluid flow across the throttle compared to the inertia of the compressor mass flow. Finally, the dimensionless time lag $\tau$ accounts for the time needed for the full development of rotating stall. According to [31], approximately seven rotor revolutions, $N=7$, were needed to full growth.

Assuming the inertial effects in the throttle duct negligible ( $G$ small) and considering the compressor pressure rise to be quasi-steady ( $\tau$ negligible small), results in the following set of equations:

$$
\begin{aligned}
& \frac{d \Phi_{c}}{d t}=B\left[\Psi_{c}-\psi\right] \\
& \frac{d \psi}{d t}=\frac{1}{B}\left[\Phi_{c}-\Phi_{t}\right]
\end{aligned}
$$

where:

$$
\begin{gathered}
\Psi_{c}=\Psi_{c, s s} \\
\Psi_{t}=\psi
\end{gathered}
$$


The Greitzer lumped parameter model is one-dimensional and can only describe the state of rotating stall, i.e., the change in dimensionless pressure rise $\psi$ and compressor mass flow $\Phi_{c}$, if the stalled characteristic is included in $\Psi_{c, s s}$. Note that no information is provided about the angular dependence of the compressor state variables $\Phi_{c}$ and $\psi$.

From the set of equations Eq.(3.3)-(3.6), it is easily verified that the compression system can be seen as a mass-spring-damper system if $\tau$ is assumed to be small, see Fig. 3.3 [34]. The

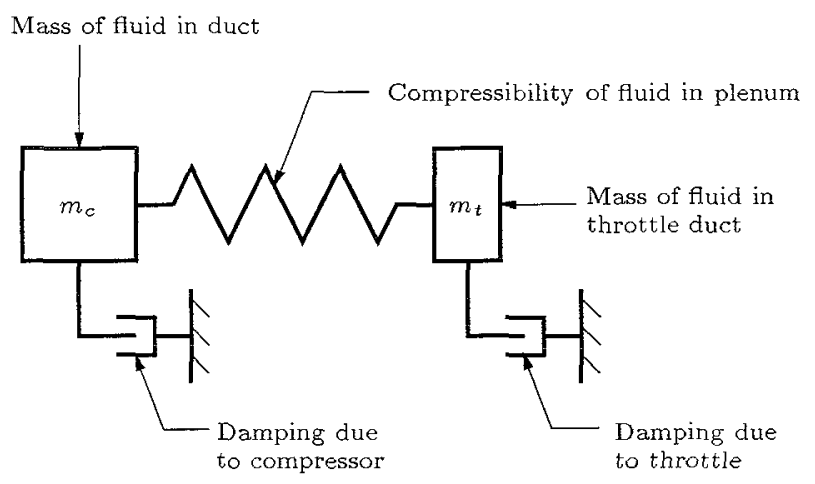

Figure 3.3: Mechanical analogue of the Greitzer lumped parameter model [34].

incompressible fluid in the compressor and throttle duct is represented by a mass $m_{c}$ and $m_{t}$ respectively and the compressibility of the fluid in the plenum by a spring; the displacement of both masses is equal to the axial displacements of the fluid in the ducts whereas the spring force is equivalent with the plenum pressure rise $\psi$. A damper with a positive damping factor describes the nonlinear behavior of the throttle and the compressor is modeled as a nonlinear damper with a damping factor that can become positive and negative (in case of net energy input by the compressor). In the author's point of view, this is equivalent to modeling the compressor as an actuator, i.e., an element that can supply and dissipate energy.

Recall that the inertance in the throttle duct is assumed to be negligible $\left(m_{t}=0\right)$, so the natural frequency of the two mass-spring-damper depicted in Fig. 3.3 is equal to the resonance frequency of the compressor-plenum subsystem [15]. This is also seen from the characteristic equation of the linearized, dimension-full version of the second order system, Eq.(3.7)(3.8) [34, Appendix]:

$$
s^{2}+\left[\frac{a^{2} L_{c}}{V_{p} A_{c}}\left(\frac{1}{\frac{d \Delta P_{T}}{d \dot{m}_{T}}}\right)-\left(\frac{d \Delta P_{c}}{d \dot{m}_{c}}\right)\right] \frac{A_{c}}{L_{c}} s+\omega_{H}^{2}\left[1-\frac{\left(\frac{d \Delta P_{c}}{d \dot{m}_{c}}\right)}{\left(\frac{d \Delta P_{T}}{d \dot{m}_{T}}\right)}\right]=0,
$$

where $\frac{d \Delta P_{T}}{d \dot{m}_{T}}$ is the slope of the throttle characteristic and $\frac{d \Delta P_{c}}{d \dot{m}_{c}}$ is the slope of the compressor characteristic. From Eq.(3.9), it is concluded that the Helmholtz frequency is equal to the resonance frequency of the compressor-plenum subsystem at the top of the compressor characteristic. Furthermore, the frequency of the surge oscillations is expected to decrease for increasing positive slopes of the compressor characteristic. Both results are in accordance with experimental results found in literature (see Section 2.2.2) and emphasize the idea of 
modeling surge oscillations by an "organ-pipe" resonator model as proposed by Emmons et al. $[22]$.

\section{Extension to Radial Compressors}

Although the Greitzer model is developed for low-pressure ratio axial compressors, Hansen et al. [40] find reasonable agreement between experimental results and simulation results of the fourth order Greitzer model for deep surge in a small single-stage radial compressor at two speeds (30000 and $54000[\mathrm{rpm}]$ ). The original Greitzer model is adapted for the radial compressor in the following way:

- Approximation of the steady compressor characteristic is split in a parabola for the measured negative flow branch and two different cubic polynomials for the unstable and stable part of the positive flow branch. As no information was available for the unstable branch, this part is estimated in such a way that a smooth interconnection with the other parts was established.

- Smaller value for $\tau$. A good fit, particularly in terms of the frequency of the surge cycle, between simulation results and measurements is obtained for $N=.5$. This value is considerably smaller than the value $N=2$ used in Greitzer's simulations [31].

Unfortunately, little data is available about surge and the time constant $\tau$ in radial compressors to verify the validity of the determined $N$-value. The simulations reasonably fit the experimental data although systematic discrepancies occur near and after flow reversal. According to Hansen et al., compressibility effects in the ducts may play an important role since they are not dealt with in the momentum balance. Pinsley et al. [56] report reasonable agreement between predictions of the lumped parameter model and experimental results for radial compressor surge as well. They conclude that the lumped parameter model quantitatively shows reasonable agreement but precise prediction of the mass flow at instability onset requires accurate information of the local slope of the compressor characteristic.

\section{Extension for Radial Compressors with Varying Rotor Speed}

Fink et al. [29] demonstrate with experiments performed on a high-speed radial compressor which is part of a small turbocharger that rotor speed variations can be important in case of deep surge. Comparison of simulation and experimental results pointed out that for small amplitude disturbances, e.g., variations associated with mild surge, the point of instability can be estimated reasonably well with the original Greitzer model. This is in agreement with the results reported in $[37,56]$. Nevertheless, in case disturbances grow to finite amplitude, rotor speed variations and a first-order time lag model for unsteady compressor pressure rise, Eq.(3.13), have to be included to describe the rotor speed increase followed by the onset and growth of mild surge oscillations. These oscillations result in mass flow reverses associated with deep surge. The introduced time lag leads to a slower growing instability and 
improves the quantitative and qualitative agreement with experimental results. The following assumptions are made in addition to the assumptions made in the original lumped parameter compression system model:

1. Choked throttle nozzle flow.

2. Throttle duct length is short (inertia effects of the fluid in the throttle duct negligible compared to inertia effects in the compressor duct).

3. Negligible gas angular momentum in the compressor passages compared to the wheel angular momentum.

4. Changes in plenum density or temperature due to given changes in plenum pressure rise can not necessarily approximated by isentropic relations [32]. More specific, the temperature ratio $\frac{T_{0 c}-T_{p}}{T_{p}}$, with the plenum inlet stagnation temperature $T_{0 c}$ and plenum temperature $T_{p}$, is not assumed to be negligible. This effect is presumably accounted for by $\frac{\tau_{p}}{\tau_{p 0}}$ in Eq.(3.11), although the compression process in the plenum is assumed to be isentropic [29]. Note that at this point a detailed understanding of the derivation of this model is lacking because the required MIT-report [28] is not available yet.

Applying conservation of momentum in the compressor duct, mass conservation in the plenum, and conservation of angular momentum in the turbocharger axis (in dimensionless form in Eq.(3.12)) leads, in combination with normalizing pressure differences by $\frac{1}{2} \rho_{a} U^{2}$, mass flows by $\rho_{a} A_{c} U$, time by $1 / \omega_{H}$, and torques by $\rho_{a} A_{c} R U^{2}$, to the following set of coupled nonlinear dimensionless equations:

$$
\begin{gathered}
\frac{d \Phi_{c}}{d t}=B\left[\Psi_{c}-\psi\right]-F B \Phi_{c} \Gamma \\
\frac{d \psi}{d t}=\frac{1}{B} \frac{\tau_{p}}{\tau_{p 0}}\left[\Phi_{c}-\Phi_{t}\right]-2 F B \psi \Gamma \\
\frac{d B}{d t}=F B^{2} \Gamma \\
\frac{d \Psi_{c}}{d t}=\frac{1}{\tau}\left[\Psi_{c, s s}-\Psi_{c}\right]
\end{gathered}
$$

where $\tau_{p}$ is the so-called instantaneous plenum temperature ratio and $F$ is defined, based on the spool inertia $I$, as:

$$
F=\frac{2 \rho_{a} L_{c} A_{c} R^{2}}{I}
$$

Recall that in the original Greitzer model for low pressure axial compressors $\frac{\tau_{p}}{\tau_{p 0}}=1$. Eq.(3.13) represents the first order transient compressor response. As in [29] the radial compressor stalls in the impeller, the time constant $\tau$ is defined as the convection time through the impeller and diffuser and is given by:

$$
\tau=\frac{1}{2} \frac{L_{m}}{L_{c}} \frac{1}{B\left|\Phi_{c}\right|}
$$

with $L_{m}$ the meridional throughflow length of the impeller and diffuser. In their simulations, Fink et al. use $\tau=0.12$ which is equivalent with approximately 2.2 rotor revolutions. This 
value corresponds to the value used by Greitzer in [31]. The variable $\Gamma$ denotes the difference between the dimensionless drive torque supplied by the turbine and the dimensionless compressor torque, i.e., $\Gamma=\Gamma_{\text {drive }}-\Gamma_{c}$. In [29], a measured torque characteristic $\Gamma\left(\Phi_{c}\right)$ is used in simulations. If this characteristic is not available, the net torque has to be determined from mass flows, pressure ratios, and inlet temperatures of the compressor and turbine, as discussed in [14, Chapter 8].

The $B$-parameter can be seen as a dimensionless rotor speed which results in two extra terms compared to the standard lumped parameter model: $F B \Phi_{c} \Gamma$ is added to the momentum equation of the compressor duct, Eq.(3.10), and $2 F B \psi \Gamma$ emerges in the mass conservation equation of the plenum, Eq.(3.11). Note that rotor speed variations are considerably smaller in large (thus, large spool inertia $I$ ) low-speed compressors.

\subsubsection{Control-Oriented High-Frequency Turbomachinery Model}

In $[6,25]$, a quasi-1D, unsteady, compressible, viscous flow model is proposed which can be applied to a generic compression system. This approach is based on an alternative dimensionless form of the system equations. The quasi-1D assumption implies that all flow properties are essentially constant in any plane normal to the axial direction. The terms control-oriented and high-frequency refer to models that are suitable for use in control design and accurately describe the relatively high-frequency (and high-amplitude) flow oscillations respectively.

Based on the principles of conservation of mass, energy and momentum and the governing equations for a calorically perfect single species gas (for a general introduction into fluid mechanics see, e.g., [46]), a set of three dimensionless, nonlinear, ordinary differential equations (ODE's) can be found after discretization:

$$
\begin{array}{r}
\epsilon \frac{d}{d t}\left[\begin{array}{c}
M_{k-1} \\
p_{k} \\
s_{k}
\end{array}\right]=\Xi(M, \gamma)\left[\begin{array}{c}
M_{k}-M_{k-1} \\
p_{k}-p_{k-1} \\
s_{k}-s_{k-1}
\end{array}\right]+\Sigma(M, \gamma)\left[\begin{array}{c}
Q \\
f_{s} \\
f_{w}
\end{array}\right] \\
+2 \Gamma(M, \gamma)\left(A_{k}-A_{k-1}\right)+\epsilon\left[\begin{array}{c}
0 \\
-1 \\
\frac{\gamma-1}{\gamma}
\end{array}\right] \frac{d A_{k}}{d t}
\end{array}
$$

with:

$$
\epsilon=L_{k} e^{-\frac{1}{2}\left(s_{k-1}+\frac{\gamma-1}{\gamma} p_{k-1}\right)}
$$

where $\gamma$ is the ratio of specific heats $\frac{c_{p}}{c_{v}}$ and the state variables of the dimensionless equations are the flow Mach number $M$, dimensionless total pressure $p$, and dimensionless specific entropy $s$, see Table 3.1 for scalings of dimensionfull variables. Furthermore, four dimensionless forcing functions can be distinguished: $Q, f_{s}, f_{w}$, and $A$. The subscripts $k-1$ and $k$ indicate the variables at the entrance and exit of the $k^{\text {th }}$ element respectively. From Eq.(3.14) it is seen that the $\epsilon$-parameter determines the relative time scales of the flow dynamics; when $\epsilon$ is very small ( $p_{k-1}$ and $s_{k-1}$ small or length $L_{k}$ small) the flow dynamics respond quasi-steadily and the forcing term with $\frac{d A_{k}}{d t}$ has little effect. 


\begin{tabular}{l|l}
\hline \hline Symbol & Description \\
\hline$R$ & Ideal gas constant \\
$\tilde{t}$ & time \\
$\tilde{L}$ & Length \\
$\tilde{A}$ & Area \\
$p_{r \in f}$ & Reference pressure \\
$T_{r e f}$ & Reference temperature \\
$\tilde{p}_{s}$ & Static pressure \\
$\tilde{T}_{s}$ & Static temperature \\
$\tilde{Q}$ & Volumetric heat transfer rate \\
$\tilde{f}_{w}$ & Specific wall friction force \\
$\tilde{f} s$ & Specific inviscid and viscous forces \\
$M=\frac{U}{\sqrt{\gamma R \tilde{T}_{s}}}$ & Mach number \\
$A=\ln \left(\frac{\tilde{\tilde{A}}}{\tilde{t}^{2} \gamma R \tilde{T}}\right)$ & Dimensionless area \\
$\tilde{p}=\tilde{p}_{s}\left(1+\frac{\gamma-1}{2} M^{2}\right)^{\frac{\gamma}{\gamma-1}}$ & Stagnation pressure \\
$\tilde{T}=\tilde{T}_{s}\left(1+\frac{\gamma-1}{2} M^{2}\right)$ & Stagnation temperature \\
$\tilde{s}=c_{p} \ln \left(\frac{\tilde{T}}{T_{r e f}}\right)-R \ln \left(\frac{\tilde{T}}{T_{r e f}}\right)$ & Entropy \\
$p=\ln \left(\frac{\tilde{p}}{p_{r e f}}\right)$ & Dimensionless stagnation pressure \\
$s=\frac{\tilde{s}}{c_{p}}$ & Dimensionless specific entropy \\
$Q=\frac{\tilde{Q} \tilde{L}}{\tilde{p} \sqrt{\gamma R \tilde{T}}}$ & Dimensionless volumetric heat transfer rate \\
$f_{w}=\frac{f_{w} \tilde{L}}{\gamma R \tilde{\tilde{T}}}$ & Dimensionless specific wall friction force \\
$f_{w}=\frac{\tilde{\tilde{f}} w}{\gamma R \tilde{T}}$ & Dimensionless specific inviscid and viscous forces \\
\hline \hline
\end{tabular}

Table 3.1: Variables in the control-oriented high-frequency turbomachinery model [25].

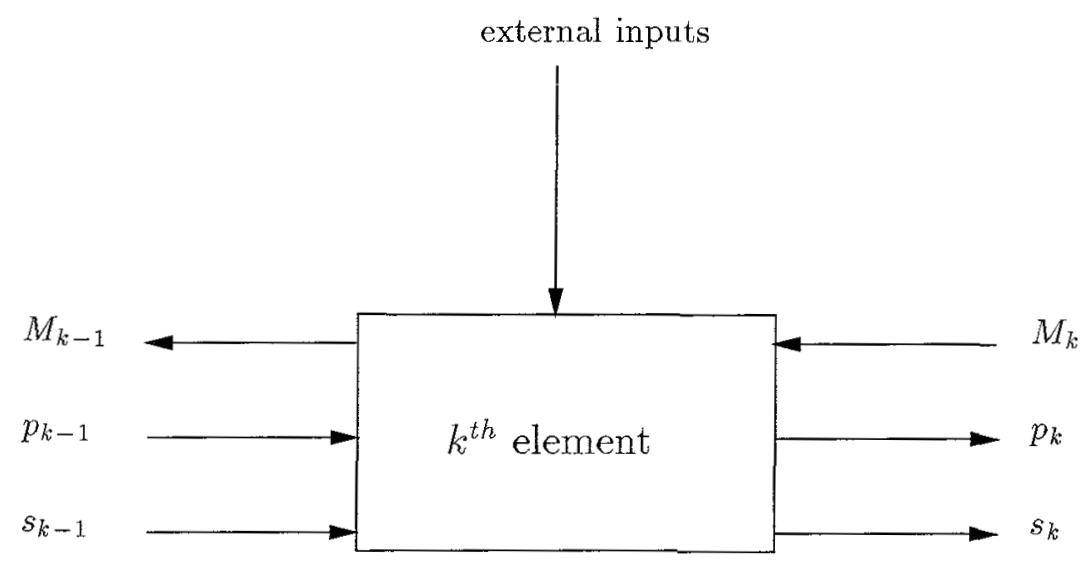

Figure 3.4: A modeling element. 
This set of fundamental dimensionless differential equations, $\mathrm{Eq}(3.14)$, can be used for modeling several components of a compression system, for instance, blading, a duct or a nozzle, and can be put in state-space form with state vector $X_{k}^{T}=\left[\begin{array}{ll}M_{k-1} & p_{k} \\ s_{k}\end{array}\right]$. A modeling element can be considered as a two port system, as shown in Fig. 3.4, which requires external inputs, e.g., rotor speed or geometry information, and the states $M_{k}, p_{k-1}$ and $s_{k-1}$ to calculate $M_{k-1}, p_{k}$, and $s_{k}$. The forcing terms in Eq.(3.14) are either determined from first principles or identification from steady-state experiments. The latter can be easily verified by substitution of the maps, $m_{4}, m_{5}$, and $m_{6}$ in Eq.(3.14):

$$
\left[\begin{array}{l}
m_{4} \\
m_{5} \\
m_{6}
\end{array}\right]=\Xi(M, \gamma)^{-1} \Sigma(M, \gamma)\left[\begin{array}{c}
Q \\
f_{s} \\
f_{w}
\end{array}\right]+2 \Xi(M, \gamma)^{-1} \Gamma(M, \gamma)\left(A_{k}-A_{k-1}\right)
$$

As a result, a turbomachinery system can be "discretisized" since the entire system can be built up in a systematic way by connecting the models of the different components, see, e.g., $[3,6,25]$. An important benefit of this discretization method is that the model is explicit so no time consuming iterations are required to compute solutions of the model.

This quasi-1D model is only capable of predicting surge. A 2D model which describes both surge and rotating stall can be developed by applying the parallel compressor concept (see [33] for further details).

\subsubsection{Botros Compression System Model}

An approach very similar to that discussed in the previous section is the systematic modeling approach developed by Botros et al. [11]. In this approach, pipe elements are described with general continuity, momentum and energy equations for one-dimensional, unsteady, compressible fluid flow while the valves, constrictions and compressors are assumed to respond in a quasi-steady manner to disturbances. This results in a set of dimensionfull nonlinear algebraic equations for characterizing the quasi-steady elements and a set of dimensionfull nonlinear partial differential equations for the pipe elements:

$$
\frac{\partial X}{\partial t}+\frac{\partial H(X)}{\partial x}+F(X)=0
$$

where $X$ is the state vector, $X^{T}=\left[\begin{array}{ll}\rho & \dot{m} P\end{array}\right]$, with density $\rho$, mass flow rate $\dot{m}$, and static pressure $P, x$ is the axial position, and $F(x)$ is the forcing term.

After linearization, the so-called transfer matrix formulation is introduced to find a solution of the gas dynamic equations:

$$
[T]\left[\begin{array}{c}
\Delta X_{k-1} \\
\Delta X_{k}
\end{array}\right]=[R]
$$

where $[T]$ is the transfer matrix, $[R]$ is the right-hand-side vector, and $\Delta X_{k}$ is given by:

$$
\Delta X_{k}=X_{k}\left(t_{n}\right)-X_{k}\left(t_{n-1}\right) .
$$


This finite difference scheme relates the change in the state vector $\Delta X_{k-1}$ at the entrance of the $k^{\text {th }}$ pipe element to $\Delta X_{k}$ at the exit. Note that this is also a two port system as depicted in Fig. 3.4.

In $[10,11]$, this approach is applied to model a gas compressor station as depicted in Fig. 3.5. In this dual-shaft arrangement, the high-pressure (HP) turbine drives a compressor and the

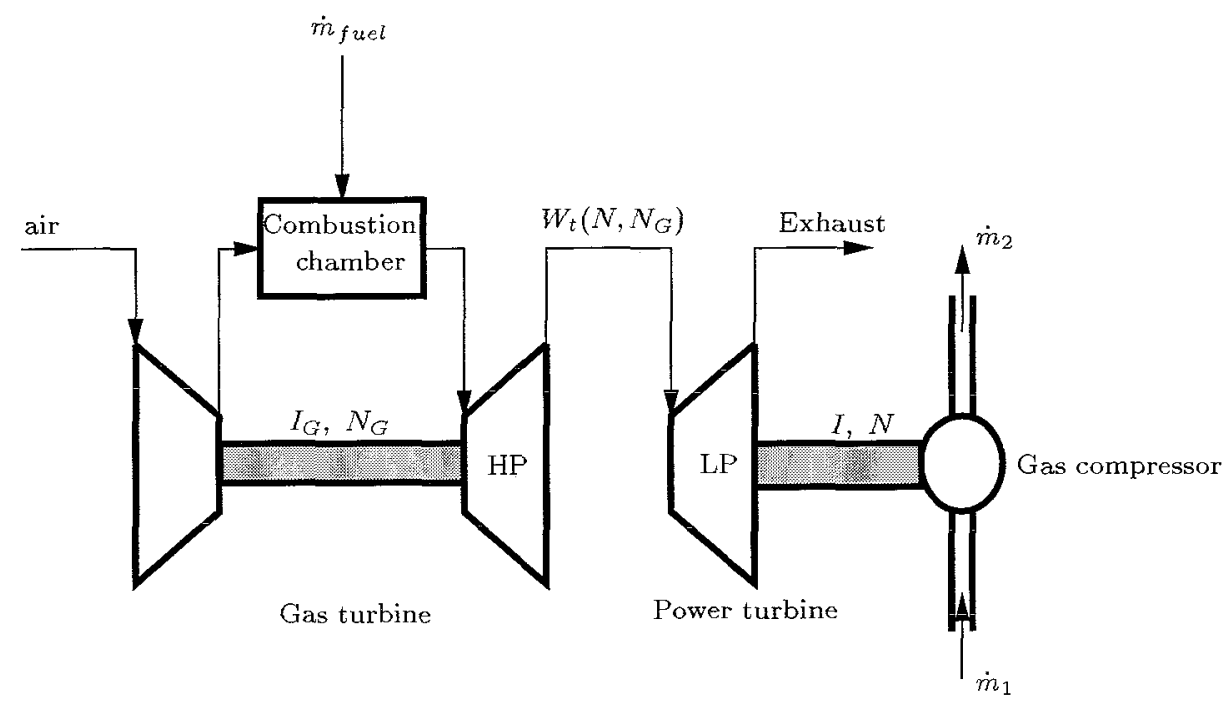

Figure 3.5: Scheme of a dual-shaft compression system [10].

combination acts as a gas generator for the low-pressure (LP) power turbine. The power turbine is mechanically independent but the shafts are thermodynamically coupled; a variation of power at the output of the power turbine is obtained by controlling the fuel flow. The gas flow through the gas compressor is approximated by a set of nonlinear equations of a polytropic process. For a constant-speed compressor, this set is sufficient to describe the behavior of the gas compressor. In case of a free-spool compressor or a variable speed compressor, additional relations are required to determine the dependency of the compressor to the varying rotational speed $N$. For the dual shaft gas turbine/power turbine configuration shown in Fig. 3.5, the following relations can be derived [10]:

$$
\begin{gathered}
I_{G} N_{G} \frac{d N_{G}}{d t}=\eta_{t}\left(N, N_{G}\right) L H V \dot{m}_{f u e l}-W_{t}\left(N, N_{G}\right) \\
I N \frac{d N}{d t}=\eta_{m} W_{t}\left(N, N_{G}\right)-\frac{H_{p}\left(Q_{a}, N\right) \dot{m}_{1}}{\eta_{p}\left(Q_{a}, N\right)}
\end{gathered}
$$

The meaning of the variables used in these equations can be found in Table 3.2.

Both quantities $W_{t}$ and $\eta_{t}$ can be described by a cubic least-square approximation in the compressor rotational speed $N$ [11]. Analogous to the Greitzer model [31], in [10] the steadystate compressor characteristic $H_{p, s s}$ is represented by a simple cubic and the compressor response to transients is modeled with a first order model. From experiments discussed 


\begin{tabular}{l|l}
\hline \hline Symbol & Description \\
\hline$\eta_{t}$ & gas turbine overall thermal efficiency \\
$\eta_{p}$ & compressor polytropic efficiency \\
$\eta_{m}$ & mechanical efficiency due to friction losses and transmission effects \\
$L H V$ & lower heating value of the fuel \\
$H_{p}$ & polytropic head for the gas compressor \\
$Q_{a}$ & actual inlet flow rate to gas compressor \\
$\dot{m}_{1}$ & gas compressor inlet mass flow rate \\
$\dot{m}_{f u e l}$ & fuel mass flow rate \\
$N_{G}$ & gas generator rotational speed \\
$W_{t}$ & power turbine output power \\
\hline \hline
\end{tabular}

Table 3.2: Variables in the Botros compression system model [11].

in [10], it is concluded that inclusion of the gas genexator and power turbine/compressor shaft inertia, $I_{G}$ and $I$ respectively, give better agreement between field measurements and simulation results for fast transients. This is in accordance with the results reported by Fink et al. [29]. This one-dimensional model can cope with both slow and rapid transients of the considered gas station but is not capable of modeling rotating stall.

\subsection{Compressor Models}

\subsubsection{Moore Model}

From the previous section, it is seen that the prediction of the compressor behavior during rotating stall requires a $2 \mathrm{D}$ mass flow description. The compressor and engine designer is especially interested in the occurrence of rotating stall because this type of instability is often more difficult to recover from due to system hysteresis.

Moore developed a theoretical framework for analysis of rotating stall in multi-stage axial compressors. The Moore model [49] describes the kinematic features of full-span stall and formulates conditions under which a traveling wave can exist even though upstream and downstream static pressure is constant. Note that rotating stall inception fell out of the scope of Moore's study.

Rotating stall is seen as an eigenmode of the system with wavelength $\pi D / n$ where $n$ indicates the number of stall cells and $D$ is the mean compressor diameter. The stalled region is modeled as a steady flow disturbance in a reference frame which is fixed to the stall cell and moves with propagation speed $f U$. In addition, the following assumptions are done:

- Compressor has a constant speed characteristic. 
- The static pressure rise in a rotor or stator row is given by:

$$
\frac{\Delta p}{\frac{1}{2} \rho U^{2}}=F(\phi)-\tau(\phi) \dot{\phi}
$$

where $F(\phi)$ is the quasi-steady pressure rise of a row and $\tau(\phi) \dot{\phi}$ accounts for hysteresis effects.

- Negligible radial effects.

- Incompressible flow in the entire system.

- Uniform flow upstream of the compressor.

- Radial and secondary-flow phenomena are disregarded.

- No flow development between every stator and rotor. Consequently, any axial disturbance proceeds straight through the compressor and is purely circumferential.

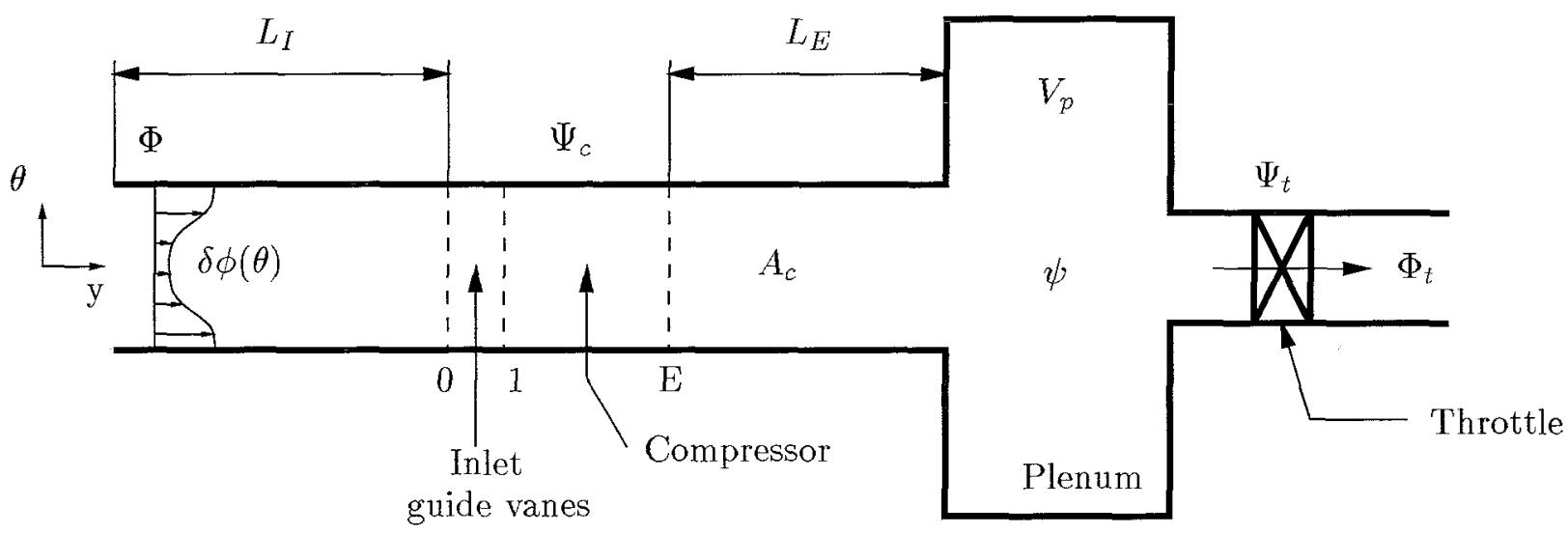

Figure 3.6: Scheme of the compression system.

As the pressure upstream and downstream of the compressor is assumed to be constant, the stage-by-stage approach leads to a momentum balance for the compressor system including the inlet and exit duct and inlet and exit guide vanes:

$$
\lambda \frac{\partial(\delta \phi)}{\partial \theta}-m f \frac{\partial(\delta \Theta)}{\partial \theta}+\frac{1}{2}\left(1-K_{l}\right)\left(\frac{\partial(\delta \Theta)}{\partial \theta}\right)^{2}+\psi-\Psi_{c}(\phi)=0
$$

where $\delta \Theta$ is the velocity potential at the compressor face, $\frac{1}{2} K_{l}\left(\frac{\partial(\delta \Theta)}{\partial \theta}\right)^{2}$ represents an abrupt pressure rise at the IGV entrance, $m$ represents the combined lag effects of entrance and exit flows, and $\lambda$ is the total time lag due to compressor blade passages. The steady axial mass flow perturbation $\delta \phi(\theta)$ on the annulus-averaged axial mass flow $\Phi$ can be determined from:

$$
\phi=\Phi+\delta \phi(\theta) .
$$


Applying Eq.(3.19) and the fact that $\delta \Theta$ is the Hilbert transform of $\delta \phi$ leads to conditions for the existence of small disturbances, finite disturbances, and a limit cycle. As the small disturbances case is of interest for the Moore-Greitzer model (Section 3.2.2), this case is discussed in the sequel. The interested reader is referred to [49] for the other cases and further details.

When the perturbations $\delta \phi$ and $\delta \Theta$ are assumed to be small, first order Taylor expansion of $\Psi_{c}(\phi)$ round the annulus-averaged mass flow $\phi=\Phi$, gives, in combination with neglecting second order terms $\delta \Theta$ in Eq.(3.19), an interesting result:

$$
\lambda \frac{\partial(\delta \phi)}{\partial \theta}-m f \frac{\partial(\delta \Theta)}{\partial \theta}+\psi-\Psi_{c}(\Phi)-\frac{d \Psi_{c}}{d \phi} \delta \phi=0
$$

As the annulus-averaged values of the perturbations $\delta \phi$ and $\delta \Theta$ are supposed to vanish, conditions can be determined for the existence of small perturbations while the pressure upstream and downstream of the compressor is constant; the operating point is on the steadystate compressor characteristic:

$$
\psi=\Psi_{c}(\Phi)
$$

In addition, as $\delta \phi$ and $\delta \Theta$ are supposed to be small periodic waves, it is found that the local compressor characteristic must be flat:

$$
\frac{d \Psi_{c}}{d \phi}=0
$$

and the propagation speed $f U$ is a function of the compressor lag parameter $\lambda$, the external duct lag parameter $m$ and the number of stall cells $n$, because $f$ can be written as:

$$
f=\frac{n}{m} \lambda
$$

Substitution of a relation for $\lambda$ (see [49, Part I] for details) yields the following result:

$$
f=\frac{\frac{1}{2}}{1+\frac{m c_{1}}{2 U n N \tau}}
$$

From this equation, it is seen that the propagation speed is less than $50 \%$ of $U$ and increasing the number of stages $N$ increases $f$ toward $\frac{1}{2}$. Additionally, multiple stall cells rotate at higher speeds. These trends are roughly consistent with experimental results $[49,41]$ although Day found an abruptly formated part-span cell rotate at $70 \%$ of the compressor speed in a fourstage axial compressor [18].

\subsubsection{Moore-Greitzer model}

Subsequent to the pioneering work of Moore discussed in the previous section, a joint work of Moore and Greitzer resulted in an incompressible fluid model for multi-stage axial compressors [50]. This model is capable of describing post-stall transients, i.e., transients subsequent to onset of compression system instabilities, associated with both surge and rotating stall. 
These transients are assumed to be initiated by unsteady axial and circumferential disturbances in the inlet duct. As in [31,33,49], rotating stall and surge are seen as eigenmodes of the compression system, with surge constituting the zeroth order mode and rotating stall representing high order modes. More specific, the surge mode is a fluctuation of the annulusaveraged compressor mass flow $\Phi$ in time while rotating stall is described as a sum of sinusoidal perturbations from $\Phi$ with wavelength $\frac{\pi D}{n}$ where $n$ corresponds to the $n^{\text {th }}$ mode and $D$ is the mean compressor diameter. The system to be analyzed is shown in Fig. 3.6 and the developed theory is based on the following assumptions:

- Expected asymmetric flow length scales are on the order of the compressor diameter.

- Large hub-to-tip radius ratio, so a two-dimensional description seems reasonable.

- Irrotational, inviscid flow in the inlet duct.

- Axisymmetric disturbances in the plenum and throttle duct.

- Incompressible compressor mass flow. This assumption seems reasonable because the Mach numbers are supposed to be small and oscillations have frequencies well below those of acoustic resonance.

- Overall pressure rise is small compared to the ambient level.

- Negligible fluid velocities and accelerations in the plenum because the plenum dimension is large compared to the ducts. As a result, the plenum is also assumed to eliminate spatial variations in mass flow so the annulus-averaged values $\Phi$ and $\Phi_{t}$ can be applied.

- Plenum pressure rise $\psi$ is the same in the entire plenum and the gas in the plenum is compressible.

- Polytropic compression process.

- Throttle duct is assumed to be short enough to neglect flow accelerations in the throttle duct. Consequently,

$$
\Psi_{t}=\psi
$$

The Moore-Greitzer model is based on the basic compressor model described in [49]. Using a stage-by-stage approach, the fluid dynamics in the inlet and exit compressor duct, inlet and exit guide vanes and each compressor stage, i.e. one stator-rotor combination, are combined in the local momentum balance. Furthermore, the annulus-averaged momentum balance Eq. (3.22) and the mass balance of the plenum Eq.(3.23) are applied to describe the dynamic behavior of the compression system. Normalizing pressures with $\rho U^{2}$, time with $U / R$, and mass flows with $\rho U A_{c}$ and using the same notation as in [45] gives the following set of coupled nonlinear differential equations:

$$
\begin{gathered}
\psi+l_{c} \frac{d \Phi}{d t}=\Psi_{c}(\Phi+\delta \phi)-m \frac{\partial(\delta \Theta)}{\partial t}+\mu \frac{\partial(\delta \phi)}{\partial t}+\lambda \frac{\partial(\delta \phi)}{\partial \theta} \\
\psi+l_{c} \frac{d \Phi}{d t}=\frac{1}{2 \pi} \int_{0}^{2 \pi} \Psi_{c}(\Phi+\delta \phi) d \theta
\end{gathered}
$$




$$
l_{c} \frac{d \psi}{d t}=\frac{1}{4 B^{2}}\left[\Phi-\Phi_{t}(\psi)\right]
$$

where $\delta \Theta$ is the velocity potential at the compressor face, $\Phi$ is the annulus-averaged axial flow coefficient, $\delta \phi$ the disturbance from its average $\Phi$ at the compressor face, $B$ is the Greitzer stability parameter, and $m, l_{c}, \mu$, and $\lambda$ are physical parameters. It is noted that $l_{c}$ is equal to the effective compressor duct length in wheel radii: $\frac{L_{c}}{r}$. The order of the equations in $\theta$ is reduced by applying a Galerkin procedure. This procedure assumes that the general solution of a differential equation can be represented by a sequence of basic functions. Moore and Greitzer assume that solutions are of the form [50]:

$$
\phi(t, \theta)=\Phi(t)+A(t) \sin (\theta+\varphi(t)) .
$$

This single-term harmonic wave approximation is most accurate for weakly nonlinear systems. Moreover, in [50] this approximation proves to be reasonable for describing transient phenomena because the amplitudes of disturbances are in reasonable agreement with calculations.

Introducing the solution for $\phi$ in the set of system equations results in [45]:

$$
\begin{gathered}
\frac{d A}{d t}=\frac{1}{\pi(\mu+\lambda)} \int_{0}^{2 \pi} \Psi_{c}(\Phi+A \sin (\theta+\varphi(t))) d \theta \\
l_{c} \frac{d \Phi}{d t}=\overline{\Psi_{c}(\Phi+A \sin (\theta+\varphi(t))}-\psi \\
l_{c} \frac{d \psi}{d t}=\frac{1}{4 B^{2}}\left[\Phi-\Phi_{t}(\psi)\right]
\end{gathered}
$$

where $\overline{\Psi_{c}}$ is the annulus-average of $\Psi_{c}$ and $\varphi(t)$ is given by [50]:

$$
\varphi(t)=\left(\frac{\frac{1}{2}}{1+m a}\right) t
$$

Solution of this set of equations requires information about the axisymmetric compressor characteristic $\Psi_{c}(\phi)$, i.e., the realized compressor performance if no time and angle dependence is permitted [50]. According to [50], the cubic approximation shown in Fig. 3.7,

$$
\Psi_{c}(\phi)=\Psi_{c 0}+H\left[1+\frac{3}{2}\left(\frac{\phi}{W}-1\right)-\frac{1}{2}\left(\frac{\phi}{W}-1\right)^{3}\right],
$$

seems a physical realistic approximation of the compressor characteristic. The parameters $H$ and $W$ have to be chosen so that the cubic approximation has the same peak and valley points as the measured compressor map.

From Eq.(3.24)-(3.26) it can be concluded that the Moore-Greitzer model couples the results of the Greitzer lumped parameter model (Section 3.1.2) and the Moore model (Section 3.2.1) and shows how surge and rotating stall are linked. In case of pure surge ( $A=0$ and no $\theta$ variation), this set of equations boils down to the two state Greitzer lumped parameter model if one realizes that the introduction of $l_{c}$ and the factor 4 are a result of a different way of normalizing pressure and time. 


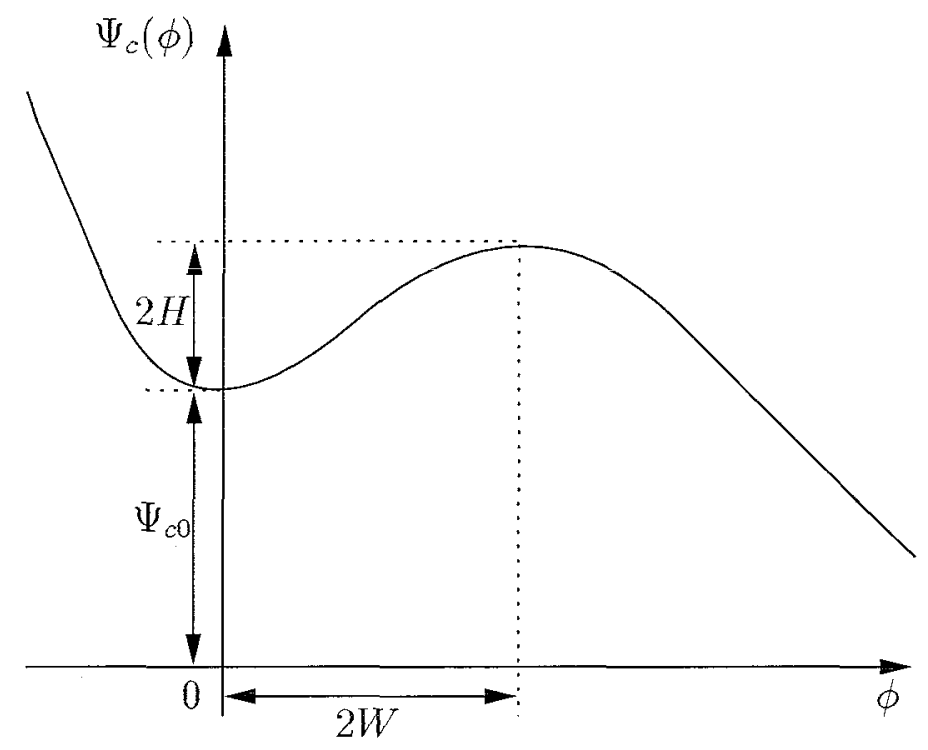

Figure 3.7: The cubic approximation of the compressor characteristic [50].

For pure rotating stall, the time derivatives of $\Phi$ and $\psi$ are zero, so Eq.(3.23) reduces to:

$$
\Phi=\Phi_{t}(\psi),
$$

and Eq.(3.21) and (3.22) boil down to the basic partial differential equation describing pure rotating stall, Eq.(3.19), for small perturbations:

$$
\psi-\Psi_{c}(\phi)=\lambda \frac{\partial(\delta \phi)}{\partial \theta^{*}}-m f \frac{\partial(\delta \Theta)}{\partial \theta^{*}}
$$

where $\theta^{*}$ is given by:

$$
\theta^{*}=\theta-f t,
$$

and $f U$ is the propagation speed of the angular disturbance.

In [65], the original Moore-Greitzer model is modified by including viscous, dissipative forces in the unsteady performance of a compressor blade row. Consequently, the local momentum balance, Eq.(3.21), results in:

$$
\psi(t)+l_{c} \frac{d \Phi}{d t}=\Psi_{c}(\Phi+\delta \phi)-m \frac{\partial(\delta \Theta)}{\partial t}+\mu \frac{\partial(\delta \phi)}{\partial t}+\lambda \frac{\partial(\delta \phi)}{\partial \theta}-\nu \lambda \frac{\partial^{2}(\delta \phi)}{\partial \theta^{2}}
$$

where $\nu$ is the viscosity of the fluid. These viscous effects are described by the last term in the right hand side of Eq.(3.29). In the original model, these viscous effects are dealt with in the compressor characteristic $\Psi_{c}(\phi)[49,45]$; the term $\tau(\phi) \dot{\phi}$ in Eq. $(3.18)$ accounts for hystesis effects due to flow acceleration, flow separation, and viscous effects in the blade passage. This time constant $\tau(\phi)$ is approximated by a value based on the inertia of the fluid in the blade passage $[49,50]$. Evidently, additional terms can be required when the viscous effects are described in an inadequate manner by $\tau(\phi) \dot{\phi}$. 


\section{Influence of the Galerkin approximation}

As the original set of equations is strongly nonlinear, it seems worthwile to apply an approximation with higher order harmonics, so the determined numerical solution can be described more accurately.

Paduano et al. [55] use the resulting equation for pure rotating stall, Eq.(3.28), as starting point for the development of an analytical control model for rotating stall. They show that higher order rotating stall modes can be described and stabilized if the Fourier series of the solution $\phi(t, \theta)$ is extended in the following way:

$$
\phi(t, \theta)=\Phi(t)+\sum_{n=1}^{\infty} A_{n} e^{s_{n} t} e^{i n \theta}
$$

with:

$$
s_{n}=\frac{r}{U}\left(\alpha_{n}-i \omega_{n}\right)
$$

where $\alpha_{n}$ and $\omega_{n}$ are the growth rate and rotation rate of the $n^{\text {th }}$ spatial harmonic respectively. Experimental results from a single stage low-speed axial compressor test rig equipped with control vanes show an increase of $11 \%$ and $18 \%$ of axial mass flow at stall compared to the uncontrolled case if the first and both first and second spatial modes are controlled respectively. This result stresses the linear and decoupled behavior predicted by Epstein et al. [23] if small-amplitude traveling waves are controlled. These results are confirmed by the experimental work of Haynes et al. [41] performed on a three stage, low-speed axial compressor with control vanes. Comparison between their data and the Moore-Greitzer model showed a lack in the prediction of the point where the compressor comes unstable; according to this model all modes become unstable if the operating point is on the positive slope of the compressor characteristic [50,41]. Modifying the Moore-Greitzer model with a time constant that accounts for the finite compressor response time due to viscous effects, the prediction of the point of instability of the investigated spatial modes and their rotational frequency improves considerably. In addition, the fact that spatial modes become unstable for different axial mass flows implies that all harmonics need not be controlled simultaneously in order to realize an increase in operating range.

\subsection{Discussion}

Table 3.3 gives an overview of some models discussed in this chapter and their properties. The models described in $[11,25]$ start from a general description by application of principles of conservation of mass, energy, and momentum for a calorically perfect gas. These models can be applied to generic compression systems and can describe the dynamic behavior of axial as well as radial compressors but they are relatively complex. Nonetheless, the controloriented high-frequency turbomachinery model [25] is used for controller design as well and shows excellent correspondence with the experimental data [3]. For dynamic analysis and controller design in axial compressors the low-dimensional Greitzer [31], Moore [49], and Moore-Greitzer [50] models can also be used. The Greitzer and Moore-Greitzer models are 


\begin{tabular}{llll}
\hline Model & Machine & Flow description & Instab. \\
\hline Botros et al. $[10,11]$ & AC & 1D Compressible & $\mathrm{S}$ \\
Eveker [25] & AC & Quasi-1D Compressible & $\mathrm{S}$ \\
Greitzer [31] & $\mathrm{A}$ & 1D Incompressible & $\mathrm{S}$ \\
Moore [49] & $\mathrm{A}$ & 2D Incompressible & $\mathrm{R}$ \\
Moore-Greitzer [50] & $\mathrm{A}$ & 2D Incompressible & $\mathrm{SR}$ \\
Fink [29] & $\mathrm{C}$ & 1D Incompressible & $\mathrm{S}$ \\
\hline
\end{tabular}

Table 3.3: Overview of model properties. Legend. Type of machine described by model - A: axial compressor, C: centrifugal compressor; Type of instability described by model-S: surge, $\mathrm{R}$ : rotating stall.

capable of predicting transients subsequent to the onset of compressor instabilities whereas the Moore model describes the kinematics of full-span stall while upstream and downstream static pressure is constant. In the Greitzer and Moore-Greitzer models, Helmholtz oscillations are assumed to cause surge, whereas in $[49,50]$ rotating stall is supposed to be the result of growing modal waves. In $[18,19]$, it is demonstrated that these assumptions do not hold in general, since (i) rotating stall can trigger surge and (ii) stall cells can be formed without modal waves. Haynes et al. [41] demonstrate that blade row time lags are important for accurately predicting the instability point of spatial harmonics. Adding a term for momentum transfer in the compressor section due to viscous effects, as in Eq.(3.29), also separates the instability point of low and higher order modes [44].

Application of the Greitzer lumped parameter model to radial compressors shows conflicting results. Hansen et al. [40] model deep surge in a small single-stage radial compressor. For a suitable choice of the time-lag associated with unsteady compressor response, the Greitzer model shows reasonable agreement with experiments. Conversely, Fink et al. [29] found poor results for deep surge in a radial compressor which is part of a small turbocharger. Inclusion of rotor speed variations significantly improved the qualitative and quantitative agreement with experiments. Rotor speed variations are also incorporated in the model developed by Botros [10].

All models listed in Table 3.3 use a steady-state compressor characteristic to specify the behavior of the compressor. Strikingly, the model used in [3] does not include any hysteretic map but is capable of predicting hysteresis effects in the onset and cessation of surge. In other words, there can exist different steady-state solutions for one parameter setting. As seen from [3], this was the result of a Hopf bifurcation point. In [32], hysteresis effects are specified by the compressor characteristic. Also, a description of the stalled characteristic is suggested in [50] which follows from the application of the Galerkin procedure. Recently, Adomaitis [1] presented a 2D incompressible flow model that is capable of predicting inception and growth of rotating stall without using a compressor characteristic. In this approach, the compressor map is replaced by so-called forcing terms in the Navier Stokes equations. These terms specify the boundary conditions and pressure fields and depend on the geometry of the blading. However, exact or numerical solution of the 3D basic partial differential equations of fluid motion are not carried out today [50]. 


\subsubsection{Discussion of Assumptions}

In the sequel of this section the effect of assumptions on the prediction capability of the different models is discussed.

\section{Length and Time Scales}

Compressor blade row performance is assumed to be quasi-steady in the Moore and MooreGreitzer model. The static pressure rise through each row is described by [49]:

$$
\frac{\Delta p}{\frac{1}{2} \rho U^{2}}=F(\phi)-\tau(\phi) \frac{d \phi}{d t}
$$

As seen in Section 3.2.2, the second term of the right hand side models non-steady blade row response due to flow acceleration, flow separation and viscous effects but in $[49,50]$ $\tau(\phi)$ is based purely on inertial effects. Wang et al. [65] introduce an extra term in the local momentum balance of the Moore-Greitzer model to account for viscous effects in the compressor blade row.

Recall that steady-state compressor characteristics are used in the models listed in Table 3.3. Since the modeling of rotating stall is focused on the unsteady local blade performance in nonuniform flow, a constraint on the wavelength has to be defined such that the blade row performance is similar to the performance for uniform flow with the same local conditions. More specific, free redistribution in a blade passage should not occur and the pressure is expected to decay limitedly. Accordingly, a blade and its neighbors ( 2 blade pitches) should have similar flow conditions and the following rough constraint for the length scale of the flow disturbance is formulated [48]:

$$
\frac{1}{4} \text { nonuniformity wavelength }>2 \text { blade pitches }
$$

As a result, it is useless to extent the order of the harmonics used in the Galerkin approximation, Eq.(3.30), considerably.

Effects due to non-steady flow have also to be small in order to apply the concept of quasisteady blade row performance. Therefore, the blade passage time has to be small compared to the blade passage time through one wavelength [48]:

$$
n f \ll \frac{2 \pi \phi}{c_{x} / r}
$$

with $n$ the spatial Fourier harmonic, $f$ the fraction of the rotor angular speed of the stall cell(s) and $c_{x}$ the blade axial chord. In addition, non-steady blade flow occurs due to acceleration of the fluid within the blade passage. This acceleration requires a non-steady pressure difference across the blade row. Typical values for $\tau$ are in the range between 0.1 and 0.3 [48]. 


\section{Compressibility effects}

From the models discussed in this report, the models of Eveker and Botros et al. (Section 3.1.3 and 3.1.4 respectively) account for compressibility effects in the ducts. In all other models examined in this study, these effects are neglected. However, it is known that this incompressibility assumption holds if [46]:

$$
M \ll 1
$$

where the Mach number $M$ is given by:

$$
M=\frac{u}{a}=\sqrt{\gamma R T}
$$

with $a$ the speed of sound. More specific, $M<0.3$ for incompressible flow [46] and, accordingly, compressibility effects will be important in high speed machines [36].

Recall that Greitzer confines his analysis in [31] to compressors with low inlet Mach numbers and pressure rises that are small compared to ambient conditions. Hence, compressibility effects of the flow in the duct can be neglected. Furthermore, compressibility effects may be important in radial compressors because they achieve generally higher pressure rises. This is endorsed by Greitzer [34] and the results found by Fink et al. [29]. As seen in the Greitzer and Moore-Greitzer model, surge only occurs in systems with compressible flows whereas rotating stall occurs in compressible as well as incompressible flows [60].

\section{Radial effects}

In the Moore and Moore-Greitzer model, the radial effects in axial compressors are assumed to be negligible for systems with a high hub-to-tip ratio. This assumption implies that the flow in the compressor annulus is a small fluid film. The values for the hub-to-tip ratio found in literature vary between 0.70 and 0.88 for axial compressors, see, e.g., [17, 32, 41]. These effects are essentially larger in radial than in axial compressors. This may also explain the bad agreement between experimental data and prediction discussed in [29].

In summary, only the Moore-Greitzer model describes both surge and rotating stall. Note that the one-dimensional surge models can be extended to $2 \mathrm{D}$ models using the parallel compressor concept [33]. 


\section{Chapter 4}

\section{Active Control of Surge and Rotating Stall}

As seen in Chapter 2, stable operation in axial and radial compressors is constrained by the occurence of surge and rotating stall. In this chapter, the stability of compression systems is analyzed (Section 4.1) and three different control concepts are discussed in Section 4.2 to suppress the unstable flow phenomena. Finally, in Section 4.3 active control systems used in experimental set-ups are summarized and compared with each other.

\subsection{Stability of compression systems}

Before starting the discussion how to suppress aerodynamic instabilities, first it seems worthwhile to examine the fundamental criteria that determine the stability of a compression system. Similar to [34], a stability analysis can be performed based on the eigenvalues of the linearized, second order Greitzer lumped parameter model, Eq.(3.7) and (3.8), discussed in Section 3.1.2. At this point, we introduce the characteristic equation presented in $[34, \mathrm{Ap}-$ pendix]:

$$
s^{2}+\left[\frac{1}{B\left(\frac{d \Phi_{t}}{d \Phi_{t}}\right)}-B\left(\frac{d \Psi_{c}}{d \Phi_{c}}\right)\right] s+\left[1-\frac{\left(\frac{d \Psi_{c}}{d \Phi_{c}}\right)}{\left(\frac{d \Psi_{t}}{d \Phi_{t}}\right)}\right]=0
$$

where $\frac{d \Psi_{t}}{d \Phi_{t}}$ is the slope of the dimensionless throttle characteristic and $\frac{d \Psi_{c}}{d \Phi_{c}}$ is the slope of the dimensionless compressor characteristic. From Eq.(4.1), it is easily verified that the linearized compression system is equivalent with a damped linear oscillator:

$$
s^{2}+2 \zeta \omega_{0} s+\omega_{0}^{2}=0
$$

This is in accordance with the mechanical analogue found in Section 3.1.2.

Application of the Routh-Hurwitz criterion learns that the system is strictly Hurwitz, i.e., all 
the roots have negative real parts, if and only if [27] (for details see, e.g., [9, Chapter 5]):

$$
\zeta \omega_{0}>0 \text { and } \omega_{0}^{2}>0 .
$$

Comparison of Eq.(4.1) and (4.2) learns that both stability conditions for the compression system depend on the slopes of the dimensionless compressor and throttle characteristics [34]:

$$
\frac{d \Psi_{c}}{d \Phi_{c}}<\frac{d \Psi_{t}}{d \Phi_{t}} \quad \text { and } \quad \frac{d \Psi_{c}}{d \Phi_{c}}<\frac{1}{B^{2}\left(\frac{d \Psi_{t}}{d \Phi_{t}}\right)}
$$

In [34], the system is called statically stable if the left-hand inequality is met. The other criterion is for dynamic stability. For a detailed discussion on static and dynamic instabilities, see, e.g., [62, Chapter 3]

Main drawback of this linear stability analysis is that the occurence of essentially nonlinear effects, e.g., large amplitude "surge cycles", can not be examined in this linear analysis. For the examination of stability of an equilibrium point of a nonlinear system, Lyapunov's direct method can be applied [59]. This method is used in [57] to investigate the stability of an equilibrium point of a compression system and its robustness to bounded disturbances.

Another approach frequently applied in literature to investigate the stability of a compression system is a bifurcation analysis, see, e.g., [4, 7, 8, 47,65]. The onset of aerodynamic instabilities is associated with a Hopf bifurcation. Further details about bifurcations can be found in [62, Chapter 7-9].

\subsection{Control of Surge and Rotating Stall}

Recall from Chapter 2 that surge and rotating stall can lead to failure of the compressor due to large mechanical and thermal loads. Suppressing these phenomena will improve maintainability and life span of the compressor [21, 23, 44]. In addition, these instabilities result in a loss in performance and efficiency $[4,10]$. Therefore, the control objective is to guarantee stable compressor operation with acceptable performance in spite of the presence of disturbances. In this section, several measures are discussed to fulfill this objective.

\section{Avoidance Control}

Conventionally, stable operation is assured by regulating the compressor's operating point to a region safely removed from the surge line (avoidance control) [10,44]. In this open-loop strategy, a control line is defined at some distance from the actual surge line, as shown in Fig. 4.1. This safety margin is set by compressor system uncertainties and disturbances, e.g., in-service deterioration, internal noise and flow distortions [4, 17, 44]. Furthermore, sensor and actuator limitations play an important role in the required size of the safety margin. If the compressor tends to cross the control line, one option is to stuck the operating point to the control line by, e.g., activating a recycle or bleed valve. An alternative approach is to 
fully open these valves so the operating point is moved far from the surge line. In the first control strategy, the compressor apparently operates in point B in Fig. 4.1 but the actual operating point of the compressor is at the same pressure but higher mass flow (point $\mathrm{C}$ ). Clearly, bleed or recycle of compressed fluid is not useful and reduces the overall efficiency. As the peak in pressure rise on a speed line and the region of low specific fuel consumption are close to the surge line, this strategy also limits the performance and efficiency of the machine $[4,44,55]$. Besides these limitations, a narrow feasible operating region restricts the

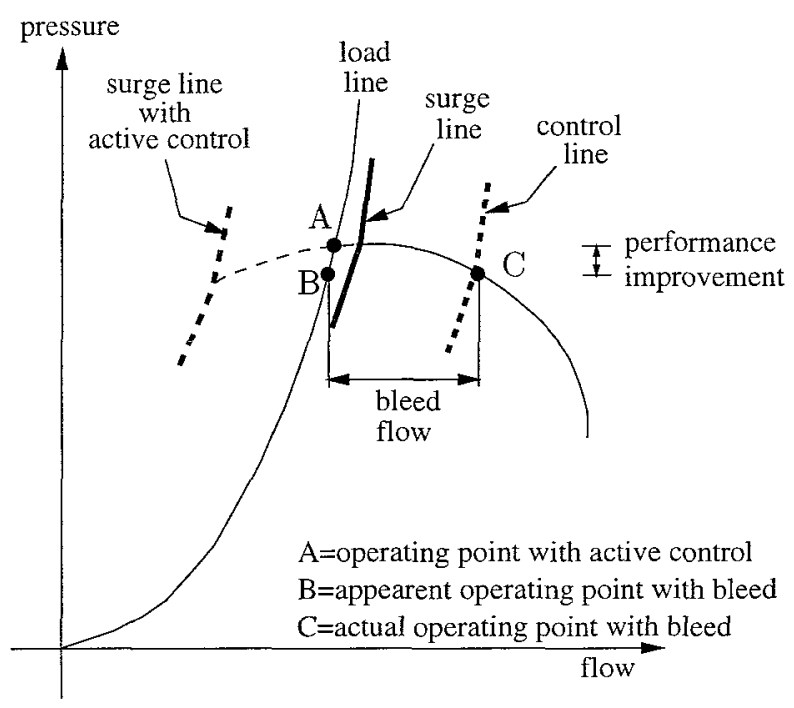

Figure 4.1: Scheme of compressor characteristic emphasizing the difference between surge avoidance control and active control.

capabilities of the machine. Under normal operating conditions, the load can change, e.g., due to shut down of downstream processes or temporal changes in the rate of production, and makes the operating point move towards the surge line, as shown in Fig. 4.2. Surge or rotating stall could be avoided by decreasing the pressure rise but this may conflict with the conceivable control objective of constant delivery pressure. This problem can be circumvented by using a compressor with a smaller capacity which prevents the system to cross the control line. However, for substantially large load changes, a larger number of compressors may be required.

Set-point changes with fixed load may also cause the compressor's operating point to cross the surge line. For instance, in a compressor system with a large plenum volume, mass flow changes will initially be substantially larger than pressure rise changes and the operating point may cross the surge line during deceleration transients, as shown in Fig. 4.3. In gas turbines with closely coupled compressor/combustor/turbine systems such as aircraft engines, the compressor's operating point may cross the surge line during acceleration transients $[14,44]$, see Fig. 4.4. During an acceleration that follows upon an increase in fuel flow, first the turbine inlet temperature will rise significantly [14, Chapter 9]. As a result, the compressor exit pressure may rise because of the increased backpressure of the turbine and the operating point may initially move towards the surge line because of the slow response 


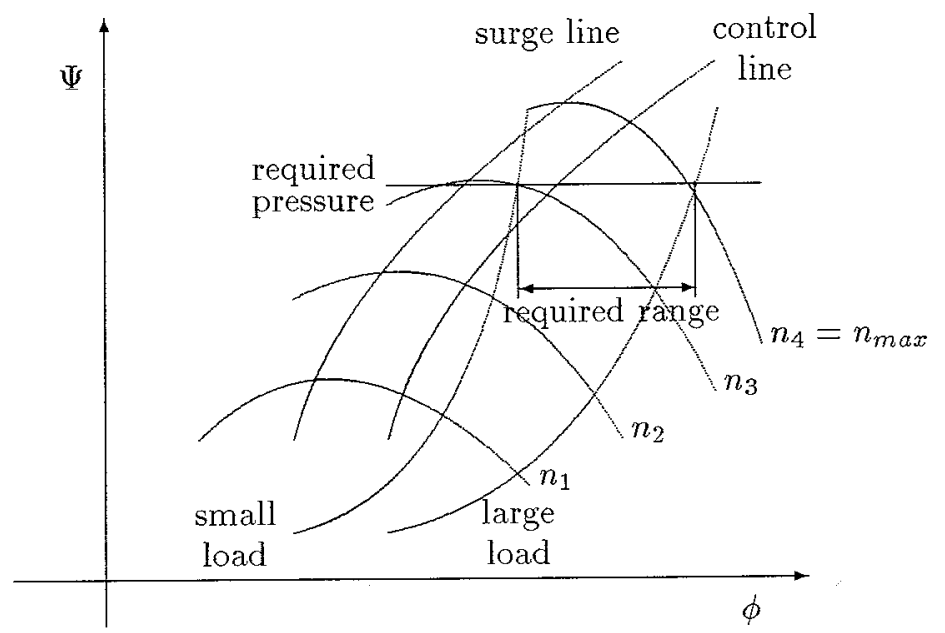

Figure 4.2: Transients due to load variations [44].

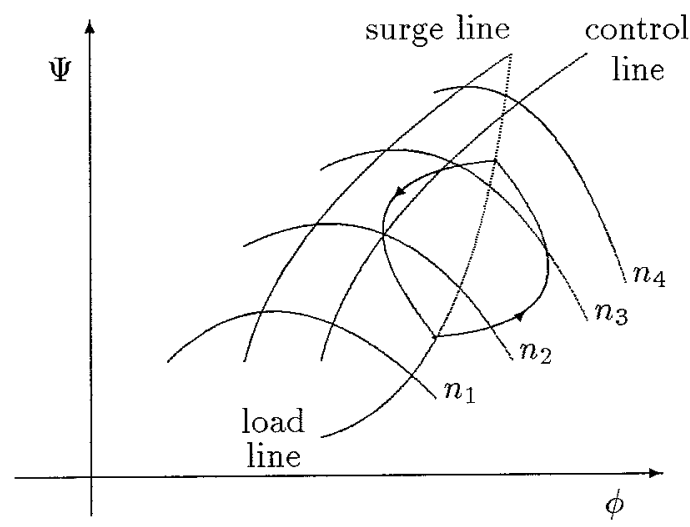

Figure 4.3: Transients in compressor systems with a large plenum [44]. 
time of compressor speed and, thus, air mass flow [44]. In both cases the system's response time to changing operation requirements is constrained by the permissible pressure rise and mass flow variations.

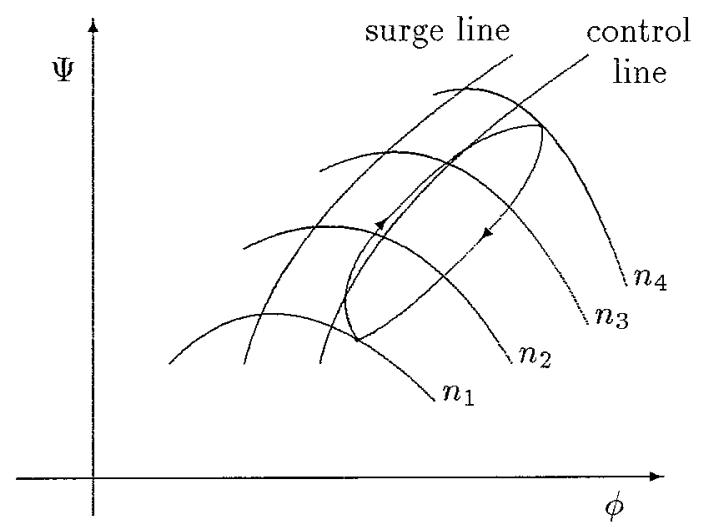

Figure 4.4: Transients in aircraft engines [44].

In summary, enlarging the feasible operating region may reduce the operating costs and the required number of compressors, thus, the investment costs, and increases the effectiveness of compressor systems [23, 44].

Several measures are proposed to increase the stable operating range of the compressor system. These measures can be grouped in two categories [12]: (i) techniques that are focussed on better compressor interior design (as discussed in, e.g., $[13,39]$ ) and (ii) techniques that attempt to suppress instabilities by control, see, e.g., [17, 44]. In this study, the focus is on control of surge and rotating stall. An overview of the current state of the art in radial compressor surge control technology can be found in [10].

To decrease the wasteful safety margin, the controller can be activated if the onset of instabilities is detected (surge detection and avoidance) [44]. But, the main disadvantages of this strategy are problems associated with the detection of the instability onset and the necessity of large control forces and fast-acting control systems.

\section{Active Control}

Epstein et al. [23] propose an analytical framework for a fundamentally different strategy: active control. This strategy is illustrated from Fig. 4.5. Active control aims at stabilizing the system beyond the "natural" surge line by appropriate control actions based on relevant information obtained from sensors. More specific, the compression system dynamics are modified by feedback of perturbations into the flow field which results in an increase of the stable operating region. The conceptual difference between avoidance control and active control is explained from Fig. 4.1; for a specific speed and load line the highest achievable 
pressure can be increased from point B to A since the active controlled compressor can operate near the peak of the speed line. Note that in conventional compressor design, the compressor is designed in such a way that the desired pressure and mass flow at the design point is at maximal efficiency given a specified stall margin. In this case, active control may not be useful since the surge line is moved towards regions with reduced compressor efficiency. Therefore, active controller design should be part of the design process because an increased operating range allows greater freedom in design $[4,56]$; the design point efficiency can be maximized for a reduced stall margin requirement and remaining design freedom can be used to address secondary design requirements such as off-design performance, weight and costs.

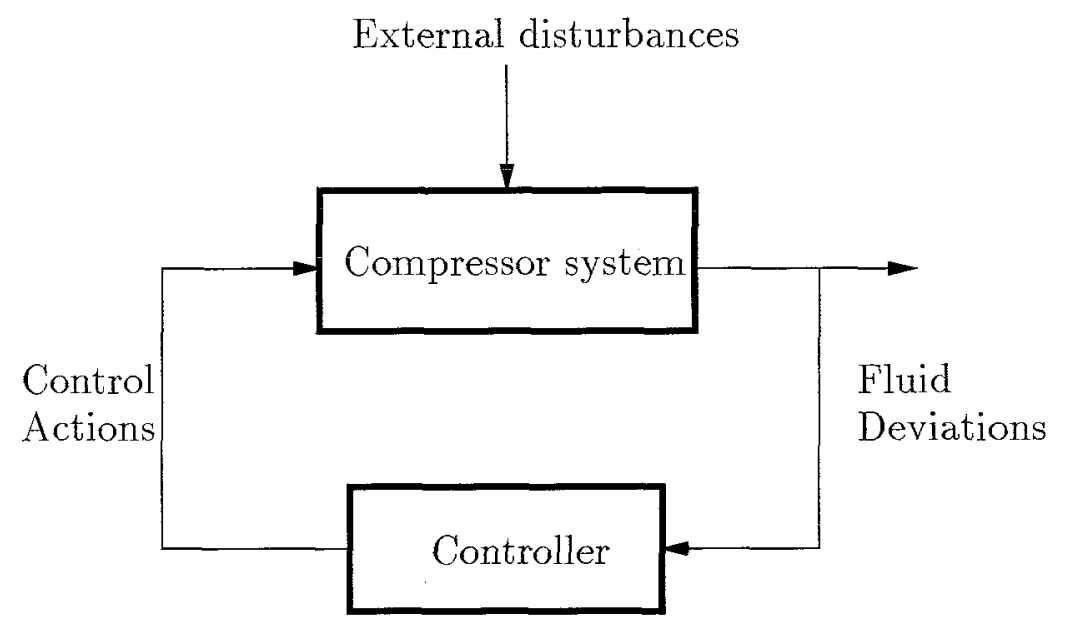

Figure 4.5: Block scheme of active control concept.

The basic idea behind the active control strategy is that rotating stall and surge start as small amplitude disturbances which can be described by linear theory. Feedback of perturbations prevent these fluid disturbances from growth into finite disturbances or a limit cycle. Accordingly, active control is often regarded as the effect of increasing the aerodynamical damping in the system $[17,23,34]$. This can be easily verified from an analysis of the linearized, second order Greitzer model for the closed loop. For instance, examination of a compressor system in which plenum pressure rise deviations $\delta \psi$ on the nominal plenum pressure rise $\psi_{0}$ are fed back to a throttle valve gives the following characteristic polynomial $[56,58]$ :

$s^{2}+\left[\frac{1}{B\left(\frac{d \Psi_{t}}{d \Phi_{t}}\right)_{K_{t 0}}}-B\left(\frac{d \Psi_{c}}{d \Phi_{c}}\right)_{\Phi_{c 0}}-\frac{Z}{B}\left(\frac{d \Phi_{t}}{d K_{t}}\right)_{\psi_{0}}\right] s+\left[1-\frac{\left(\frac{d \Psi_{c}}{d \Phi_{c}}\right)_{\Phi_{c 0}}}{\left(\frac{d \Psi_{t}}{d \Phi_{t}}\right)_{K_{t 0}}}+Z\left(\frac{d \Phi_{t}}{d K_{t}}\right)_{\psi_{0}}\left(\frac{d \Psi_{c}}{d \Phi_{c}}\right)_{\Phi_{c 0}}\right]=0$

where:

$$
u=Z \delta \psi
$$

with proportional feedback gain $Z$ and small throttle parameter variations $u$ from the nominal value $K_{t 0}$. Comparison of Eq.(4.1) and (4.3) shows that active control modifies the damping as well as the natural frequency of the linearized system. It is remarked that the turbomachinery community qualifies flow deviations and perturbations as disturbances. But, in control theory 
disturbances are signals which cannot be manipulated and which denote the effect that the external world has on the system, see, e.g., [61].

Energy considerations point out that (periodic) oscillations can occur near the peak of the positively sloped part of the compressor map if the net mechanical energy provided by the compressor balances the dissipation in the system over a cycle [34]. Epstein et al. [23] show that active control can effect this energy balance by direct energy production or dissipation and by affecting the balance between elements that produce and absorb energy. Experimental work of Day indicates that this strategy does not work for stall cells that emerge without precursive build-up [17]. In that case, stabilization can be realized by locally energizing the flow in the vicinity of the instability and make it more disturbance tolerant. As this control strategy is based on the feedback of flow deviations, relatively little control power is required. Control of these aerodynamic instabilities in their initial stage allows surge and rotating stall to be treated separately because their behavior is linear and decoupled [41]. Ffowcs Williams et al. [26] use this property to control rotating stall and surge separately with two independent, linear controllers. Furthermore, in $[27,37,56]$ the proportional controller is also effective in the control of large amplitude oscillations.

\subsection{Active Control Systems}

Active control systems consist of sensors for detection of fluid disturbances, actuators to introduce desired perturbations and a suitable controller that determines the most optimal actuator actions from sensor information [58]. Section 4.3.1 outlines the sensors and actuators proposed for surge and rotating stall control in experimental set-ups. A brief overview of applied control schemes is given in Section 4.3.2.

\subsubsection{Sensors and Actuators}

Table 4.1 gives an overview of sensor-actuator pairs applied in experimental studies. Five candidate sensors and seven candidate actuators are depicted in Fig. 4.6.

\section{Surge Control}

From Table 4.1, it can be concluded that surge can be stabilized by a single actuator (often called 1D actuator). Furthermore, a single sensor provides sufficient information to the controller. An analysis [64, Chapter 3] of the linearized Greitzer model shows that the compressor system is controllable and observable if a single actuator and sensor is used from those mentioned in [58]. Experimental results demonstrate that significant shifts can be achieved in surge point mass flow, as predicted by Epstein et al. [23]. For example, in [37, 56], 25\% decrease in mass flow at the surge point is reported in a radial compressor whereas Ffowcs Williams and Huang [27] achieve approximately $20 \%$ reduction in mass flow using a loud- 


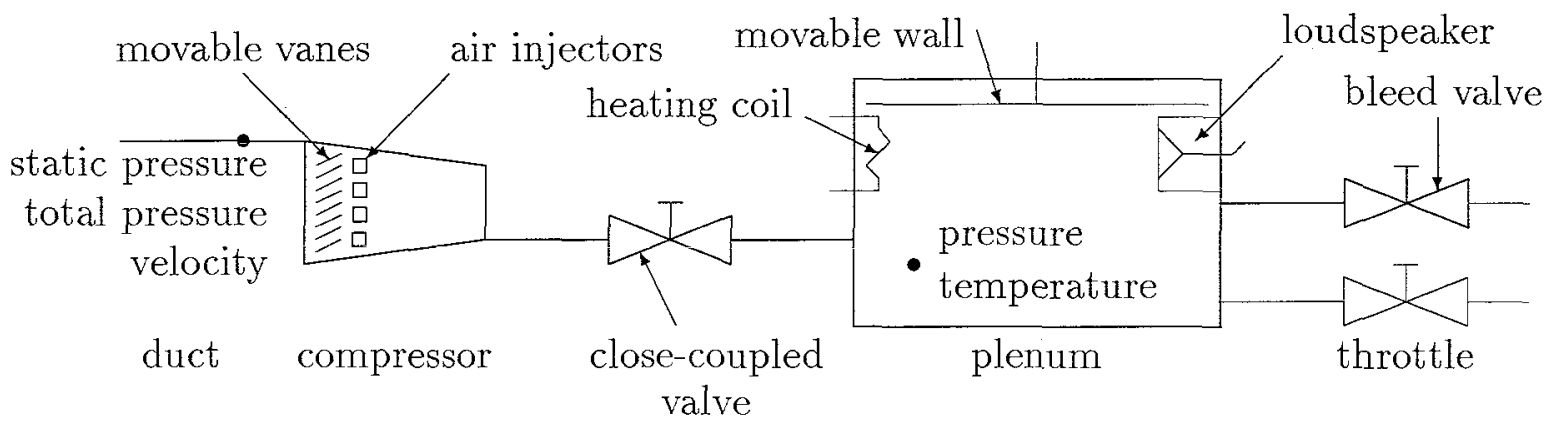

Figure 4.6: Compressor system with potential sensors and actuators [44].

speaker. Note that the movable wall in [37] is a passive element since no energy is fed into the compressor system; the plenum pressure oscillations are damped by dissipation of the kinetic energy in the damper attached to the movable wall.

Table 4.1: Overview of sensors, actuators, and control schemes applied in active control experiments. Legend: Type of machine - A: axial, C: centrifugal, l: low speed, s: singlestage, m: multi-stage. Control of type of instability - S: surge, R: rotating stall. Treatment - E: experimental, A: analytical. Model used for analysis - G: Greitzer, M: Moore, MG: Moore-Greitzer, HF: Control-oriented high-frequency turbomachinery model.

\begin{tabular}{rlllllll}
\hline \hline & Mach. & Inst. & Treatm. & Sensor & Actuator & Control & Model \\
\hline$[3]$ & As & S & EA & plenum press. & throttle & Ho loop shaping & HF \\
{$[7]$} & Al & S & EA & dyn. inlet press. & throttle & I/O feedback lin. & G \\
{$[27]$} & C & S & E & diffuser press. & loudspeaker & prop. feedback & G \\
{$[37]$} & C & S & EA & plenum press. & movable wall & structural feedback & G \\
{$[56]$} & C & S & EA & plenum press. & throttle & prop. feedback & G \\
{$[5]$} & Als & R & E & stat. inlet press. & throttle & nonlin. feedb. & MG \\
{$[8]$} & Al & R & EA & stat. inlet press. & air injectors & prop. feedback & MG \\
{$[38]$} & Als & R & EA & stat. inlet press. & air injectors & aeromech. feedback & - \\
{$[41]$} & Alm & R & EA & hot wires & movable IGV's & prop. feedback & MG \\
{$[55]$} & Als & R & EA & hot wires & movable IGV's & prop. feedback & MG \\
{$[17]$} & Alm & SR & E & hot wires & air injectors & prop. feedback & - \\
{$[26]$} & C & SR & EA & diffuser press. & loudspeaker & prop. feedback & M \\
\hline \hline
\end{tabular}

Most of these experiments are show cases to examine the active control concept. For practical applications, however, it is worth investigating which type of sensor and actuator is most suitable for surge control. In [58], the effect of five actuators and four sensors among those shown in Fig. 4.6 is studied on the performance of the control system. Based on an analysis of the linearized second order Greitzer model [31], the maximal stabilizable compressor slope is determined for the sensor-actuator pairs under consideration using proportional feedback. A close-coupled valve or an injector as actuator in combination with a mass flow sensor appear to be most promising. Additionally, Simon et al. examined the influence of actuator bandwidth 
and disturbance type on controlled compressor performance. As seen from the quantitative analysis in [64], the effect of type, position, and number of sensors and actuators seems worth further investigation.

\section{Rotating Stall Control}

Control of rotating stall requires information about the non-uniformity of the flow, so an array of sensors placed around the circumference of the compressor is used. In literature, this array of sensors is often called a 2D sensor which is in contrast with a single or 1D sensor. Analogous, 1D and 2D actuators can be distinguished. Badmus et al. [4] found the linearized compressor dynamics about the unstable equilibrium points to be linearly uncontrollable and unobservable if $1 \mathrm{D}$ actuation and annulus-averaged sensing is applied. Considering this result, they conclude that 2D sensors and 2D actuators are required for linear feedback stabilization.

From Table 4.1 it is seen that common realizations of $2 \mathrm{D}$ sensors are arrays of pressure transducers $[5,8,26]$ and hot wire anemometers $[17,41,55]$. To stabilize rotating stall, movable inlet guide vanes (IGV's) [41,55] and an array of air injectors $[8,17,38]$ are employed. Paduano et al. [55] demonstrate a decrease in stall mass flow of $23 \%$ in a single-stage axial compressor using movable IGV's while Haynes et al. [41] found an $8 \%$ decrease in a threestage axial compressor. Moreover, a $10 \%$ reduction in stalling mass flow was realized using aeromechanical feedback [38]. In this approach, circumferentially placed air injectors are used which are "activated" by small, local pressure perturbations acting on the construction. In [17], two control strategies are used to suppress rotating stall disturbances: (i) control of the first mode of rotating stall by feedback of mass flow disturbances and (ii) simultaneously open all air injectors (one-dimensional actuator). Both strategies result in a reduction in mass flow at the new rotating stall point of approximately 5\%. The stable operating range can be extended further if the second mode of the rotating stall wave is also controlled [41, 55]. But, Haynes et al. report no additional decrease in stall mass flow if the third harmonic is controlled in addition to the first and second harmonics of the rotating stall wave.

Important drawbacks of the use of $2 \mathrm{D}$ actuation and $2 \mathrm{D}$ sensing are the complexity and high costs due to the large number of required sensors and actuators and the relatively high bandwidth requirements because of the speed and higher harmonics of the rotating disturbance [4]. Badmus et al. [5] show that control of rotating stall is also possible by using a $2 \mathrm{D}$ sensor combined with a single, low-bandwidth $1 \mathrm{D}$ actuator. In contrast with approaches which use rotating stall phase information $[41,55]$, the nonlinear controller in this simplified approach acts directly on disturbances from an equilibrium point, so bandwidth requirements are relatively low. In [26], a nonaxisymmetric mode is stabilized by using $2 \mathrm{D}$ diffuser channel pressure measurements and a $1 \mathrm{D}$ loudspeaker.

For rotating stall in axial compressors, the influence of actuator and sensor choice on controller performance is studied in [42]. In this theoretical study, four actuators are considered, namely, circumferentially arrays of jets, intake ports and movable IGV's upstream of the compressor and bleed valves downstream of the compressor. These actuators are used in combination with an array of a velocity, static pressure, or total pressure sensors. These actuators and 
sensors are close-coupled with the compressor, i.e., placed at a distance smaller than the disturbance wavelength from the compressor. A modified version of the Moore model is used to analyze the performance of all sensor-actuator pairs using proportional feedback. As in [58], the maximum stabilizable compressor slope is the most important performance criterium and, moreover, the effects of sensor location, actuator bandwidth and controller phase are determined. This study indicates the array of jets and the velocity sensor as most promising actuator and sensor, respectively, for rotating stall control. But, static or total pressure measurements might be more practical in high-speed compressors than hot wire measurements [42]; important disadvantages of the usage of hot wires are the noisy measurement signals [4] and their fragility.

\subsubsection{Controllers}

The "first generation" of controllers implemented in experimental set-ups [17, 26, 27, 41, $55,56]$ are based on linear feedback stabilization [4], see Table 4.1. These controllers aim at stabilizing unstable operating points by linear feedback in order to enlarge the stable operating region. The motivation for this approach is that stable compressor operation under disturbances can be guaranteed as long as the stable operating point stays inside the stable operating region. In order to realize this, Epstein et al. [23] propose a so-called complex-valued proportional feedback control law [55] which is given in the frequency domain by:

$$
Z=|Z| e^{j \beta}
$$

where $|Z|$ is the modulus of $Z$ and $\beta$ is a temporal (for surge control) or spatial (for rotating stall control) phase shift. This proportional feedback controller describes the gain and phase relation between the sensed perturbation signal and the control signal.

For surge control, suitable values for gain and phase-shift are determined from a stability analysis of the linearized Greitzer model $[23,27,56]$. From these analytical studies, it is concluded that the choice of both variables significantly influences the effectiveness of the controller since the reduction in stall mass flow can be increased by a proper choice of $\beta$ compared to a simple proportional controller $(\beta=0)$ for the same value of $|Z|[23]$. In [56], stable operating regions for $|Z|$ and $\beta$ are computed as a function of the Greitzer stability parameter $B$, see Fig. 4.7. This figure illustrates that an appropriate choice of $|Z|$ and $\beta$ becomes more important for higher values of $B$. More specific, high $B$-values limits the effectiveness of the controller since the freedom of choice in $\beta$ decreases substantially. Note that a wrong choice of $\beta$ can cause instability. As in $[27,56]$ the phase-shift $\beta$ is constant for all frequencies, practical implementation of this controller seems not to be straight forward but detailed information about the implementation on an experimental set-up can not be found in literature. For example, in [27] the measured plenum pressure signal is processed in a phase shifter and amplifier to generate the desired signal for the loudspeaker. So far, we assume that measurements are (discrete) Fourier transformed before they are processed in the controller.

In $[17,41,55]$, the complex-valued rotating stall controller obtains measurements from several sensors placed around the circumference. The sensed perturbations can be represented as a 


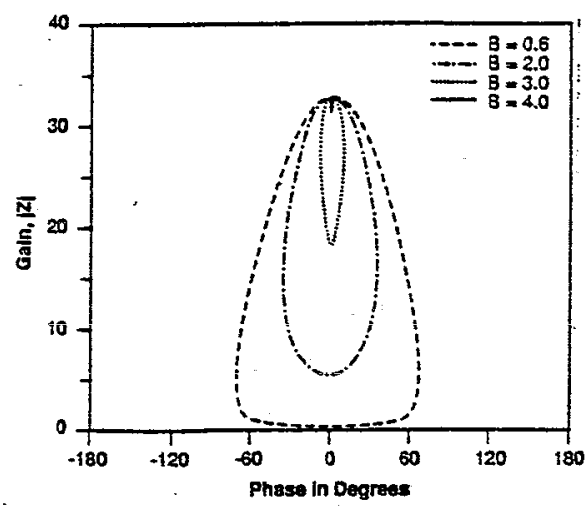

Figure 4.7: Example of stability regions using complex-valued proportional feedback [56].

Fourier series. For example, mass flow perturbations $\delta \phi$ can be written as:

$$
\delta \phi=\sum_{n=-\infty}^{\infty} \delta \tilde{\phi}_{n} e^{|n| \frac{x}{r}}, \quad x<0
$$

where $x$ is the distance from compressor face and $r$ is the radius of the machine. The $n^{\text {th }}$ spatial Fourier transform $\delta \tilde{\phi}_{n}$ is of the form $[41,55]$ :

$$
\delta \tilde{\phi}_{n}=e^{j\left(n \theta-\omega_{n} t\right)} e^{\alpha_{n} t}
$$

The rotation and growth rate of the $n^{\text {th }}$ spatial harmonic is represented by $\omega_{n}$ and $\alpha_{n}$ respectively and $\theta$ is the circumferential position. As the system's behavior is linear and decoupled if perturbations are at small amplitude, each spatial harmonic can be controlled by a separate feedback controller [41]. At each instant $t$, the measurements from the $K$ sensors are Discrete Time Spatial Fourier transformed in order to decompose these measured signals into spatial harmonics [55]:

$$
\delta \tilde{\phi}_{n}(t)=\frac{1}{U} A_{n}(t)=\frac{1}{U} \frac{1}{N} \sum_{k=1}^{K} C_{k}(t) e^{-j n \theta_{k}}
$$

where $\theta_{k}$ is the angular position of the $k^{t h}$ sensor:

$$
\theta_{k}=\frac{2 \pi k}{K}
$$

$n$ represents the order of the spatial harmonics, and $C_{k}(t)$ is given by:

$$
C_{k}(t)=\sum_{n=-\infty}^{\infty} A_{n}(t) e^{j n \theta_{k}}
$$

The rotating stall controller describes the relation between sensed perturbations and control actions for each spatial harmonic to be controlled. In this case, the phase $\beta_{n}$ represents the spatial lag for the $n^{\text {th }}$ controlled spatial harmonic. The effect of gain and phase on the point of instability is studied from the linearized Moore-Greitzer model [50]. Remark that $n$ is smaller than half of the number of sensors due to the Nyquist frequency limit. Application of complex-valued proportional feedback to experimental set-ups shows promising results for surge control $[27,56]$ and rotating stall control $[41,55]$. 
An important drawback of complex-valued proportional feedback is the limited operating region where the controller is valid due to the linearized models used for controller design. Gain scheduling can circumvent this design problem. Nevertheless, nonlinear controllers deal directly with nonlinearities and they are expected to enlarge substantially the domain of attraction of an equilibrium point $[4,59,65]$. Recently, a few nonlinear surge controllers have been proposed: e.g., a quadratic feedback law [65], a nonlinear model-based input-output feedback linearizing controller [7], a back stepping design [30, 45] and a $\mathcal{H}_{\infty}$ controller [3, 64]. In [7], the response of a compression system with a nonlinear controller to large rapid set-point changes is compared with a conventional PD controller. Both controllers stabilize the system beyond the "natural" surge line with comparable control action. However, the compression system with the nonlinear controller shows fewer excursions than the linear controller.

Badmus et al. [5] control rotating stall by nonlinear feedback disturbance rejection. In this approach, a nonlinear controller is designed to attenuate the effects of the disturbances on the equilibrium point. For further details about this approach, see, e.g., [52, Chapter 7]. In [5], persistent and impulsive disturbances are directly addressed by feeding back the amplitude of the first harmonic of the rotating stall wave to the throttle valve. 


\section{Chapter 5}

\section{Conclusions and Future Research}

In this report an overview is presented of the current status of active control of rotating stall and surge. However, by no means this overview is supposed to be exhaustive. This chapter summarizes the main conclusions of this literature study and mentions some directions for future research. A distinction is made between conclusions and recommendations concerned with the modeling of compressor flow dynamics and those related to its control.

\subsection{Modeling of Compressor Flow Dynamics}

Aerodynamic flow instabilities are generally much better understood in axial than in radial compressors

Although a considerable amount of published research is available about rotating stall and surge, a model that describes the main features of various types of these aerodynamic flow instabilities is lacking, particularly for radial compressors. Nevertheless, the behavior of compressor systems subsequent to instability onset is reasonably grasped although unstable flow phenomena in axial compressors are generally much better understood than in radial compressors. The main reason for this deficiency for radial compressors may be the strong dependence of the type of the occurring aerodynamic flow instabilities on compressor configuration and physical parameters [29]. Recall that system stability is influenced by the matching of several components and their geometries vary in a wide range. The shape of the compressor characteristic and hysteresis effects are also assumed to play an important role in the type of instability met. Note that the classification of different types of rotating stall and surge is not unique [44].

Rotating stall is supposed to be dominant in low-speed axial compressors while surge occurs at relatively high speeds in both axial and radial compressors [34]. Although rotating stall is encountered in radial compressors as well, its effect on the performance of radial machines is often believed to be small. Moreover, compressors are more likely to show disturbances 
associated with rotating stall than surge if the plenum volume is decreased. Both influences of rotor speed and plenum volume are captured by the Greitzer [31] and Moore-Greitzer model [50].

Moore-Greitzer model can describe the behavior of the compressor system subsequent to the onset of rotating stall and surge

So far, only the Moore-Greitzer model can describe the possible growth and decay of axial and circumferential perturbations into rotating stall and surge during transients. This model seems an useful starting point for further investigation although it is not capable of describing the formation of finite stall cells without modal perturbations $[18,44]$. One point of interest is the extension of the Moore-Greitzer model to radial compressors and the prediction capability in case axial as well as circumferential disturbances are present in the system. Another research topic may be the parallel compressor concept [33] which enables the extension of existing one-dimensional models to two-dimensional models [3]. Moreover, research into the modeling of $3 \mathrm{D}$ flow phenomena [48], e.g., part-span stall, is a prospective challenge.

\subsection{Control of Compressor Flow}

\section{Rotating stall and surge control by complex-valued proportional feedback shows promising results}

Considering the experimental results presented in literature, it is concluded that active surge control is still in a research stage but actual implementation in industrial practice seems at hand. Recently, promising results have been achieved in the field of rotating stall control as well $[5,41,55]$, but control of rotating stall in multi-stage high-speed axial compressors is claimed to be a difficult problem [44]. In particular rotating stall control has to be further developed before implementation in standard compressor pressure and capacity control systems is possible. In the first rotating stall and surge control systems, complex-valued proportional feedback controllers are used which can realize a reduction in mass flow at the instability point between $5 \%$ and $25 \%$. Additional research into complex-valued proportional feedback is required to gain insight in: (i) the details behind the practical implementation and (ii) the benefits of this controller in relation to standard control concepts. From the author's point of view, the damping and natural frequency in Eq.(4.3) can also be easily adapted by using, e.g., conventional PD control.

Nonlinear controllers are expected to improve the performance of the compressor system

Improvement of the prediction capability of compression system models will be beneficial for model-based controller design. As discussed in the previous paragraph, apart from a 
few exceptions, only simple proportional feedback controllers are used currently to stabilize the compression system. Up to now, little attention is paid to disturbance rejection and robustness of the closed loop. More advanced, nonlinear controllers are expected to realize some performance improvements. Further fields worth investigating are the influence of sensors and actuators on controller effectiveness, the development of high-bandwidth valves, and integrated control of surge and rotating stall.

In summary, a better understanding of the mechanism(s) behind the onset of aerodynamic flow instabilities may allow refinements to existing models and may give new insights into methods of suppressing these instabilities. 


\section{Bibliography}

[1] Raymond A. Adomaitis. Spatially resolved compressor characteristics for modeling and control of blade-scale flow instabilities. In Proc. 1995 SPIE Int. Symp. on Sensing, Actuation and Control in Aeropropulsion, volume 2494, pages 36-46, Orlando, FL, April 1995.

[2] O.O. Badmus. Nonlinear dynamic analysis and control of surge and rotating stall in axial compression systems. PhD thesis, Georgia Institute of Technology, March 1994.

[3] O.O. Badmus, S. Chowdhurry, K.M. Eveker, and C.N. Nett. Control-oriented high-frequency turbomachinery modeling: single-stage compression system one-dimensional model. ASME J. Turbomachinery, 117(1):47-61, January 1995.

[4] O.O. Badmus, S. Chowdhurry, K.M. Eveker, C.N. Nett, and C.J. Rivera. A simplified approach for control of rotating stall. Part 1: Theoretical development. In Proc. of the 29th Joint Propulsion Conference, Monterey, June 1993. AIAA. Paper No. 93-2229.

[5] O.O. Badmus, S. Chowdhurry, K.M. Eveker, C.N. Nett, and C.J. Rivera. A simplified approach for control of rotating stall. Part 2: Experimental results. In Proc. of the 29th Joint Propulsion Conference, Monterey, June 1993. AIAA. Paper No. 93-2234.

[6] O.O. Badmus, K.M. Eveker, and C.N. Nett. Control-oriented high-frequency turbomachinery modeling: general 1D model development. J. Turbomachinery, 117(3):320-335, July 1995.

[7] O.O. Badmus, S.Chowdhurry, and C.N. Nett. Nonlinear control of surge in axial compression systems. Automatica, 32(1):59-70, January 1996.

[8] Robert L. Behnken, Raffaello D'Andrea, and Richard M. Murray. Control of rotating stall in a lowspeed axial flow compressor using pulsed air injection: modeling, simulations and experimental validation. In Proc. of the 34th IEEE Conference on Decision and Control, volume 3, pages 3056-3061, New Orleans, LA, December 1995.

[9] Okko H. Bosgra and Huibert Kwakernaak. Design methods for control systems. Notes for a course of the Dutch Institute of Systems and Control (DISC), winter term 1995-1996.

[10] K.K. Botros. Transient phenomena in compressor stations during surge. ASME J. Engineering for Gas Turbines and Power, 116(1):133-142, January 1994.

[11] K.K. Botros, P.J. Campbell, and D.B. Mah. Dynamic simulation of compressor station operation including centrifugal compressor and gas turbine. ASME J. Engineering for Gas Turbines and Power, 113:300-311, April 1991.

[12] K.K. Botros and J.F. Henderson. Developments in centrifugal compressor surge control - A technology assessment. ASME J. Turbomachinery, 116(2):240-249, April 1994.

[13] H.P. Buse, F.M. de Jongh, and F.H. Vial. Performance improvement of low volume flow centrifugal compressor stages. In Proc, of the 6th European congress on fluid machinery for the oil, petrochemical and related industries, volume C508/033/96, The Hague, The Netherlands, June 1996. 
[14] H. Cohen, G.F.C. Rogers, and H.I.H. Saravanamuttoo. Gas turbine theory. Longman Scientific \& Technical, London, 3rd edition, 1987.

[15] N.A. Cumpsty. Compressor aerodynamics. John Wiley \& Sons, New York, 1989.

[16] Raffaello D'Andrea, Robert L. Behnken, and Richard M. Murray. Active control of an axial flow compressor via pulsed air injection. Technical report, California Institute of Technology (CALTECH), CIT/CSD 95-029, July 1996.

[17] I.J. Day. Active suppression of rotating stall and surge in axial compressors. ASME J. Turbomachinery, 115(1):40-47, January 1993.

[18] I.J. Day. Stall inception in axial flow compressors. ASME J. Turbomachinery, 115(1):1-9, January 1993.

[19] I.J. Day. Axial compressor performance during surge. J. Propulsion and Power, 10(3):329-336, June 1994

[20] R.C. Dean and L.R. Young. The time domain of centrifugal compressor and pump stability and surge. ASME J. Fluids Engineering, 99:53-63, March 1977.

[21] D. deSa and S. Maalouf. The operating and control philosophy of turbo-compressors. Measurement and Control, 29(3):69-72, April 1996.

[22] H.W. Emmons, C.E. Paerson, and H.P. Grant. Compressor surge and stall propagation. ASME Transactions, 77:455-469, May 1955.

[23] A.H. Epstein, J.E. Ffowcs Williams, and E.M. Greitzer. Active suppression of aerodynamic instabilities in turbomachines. J. Propulsion, 5(2):204-211, March 1989.

[24] Harm van Essen. Compressor modeling and control. Technical Report WOC-WET 95.056, Fac. of Mechanical Engineering, Eindhoven University of Technology, 1995.

[25] K.M. Eveker. Model development for active control of stall phenomena in aircraft gas turbine engines. PhD thesis, Georgia Institute of Technology, September 1993.

[26] J.E. Ffowcs Williams, M.F.L. Harper, and D.J. Alwright. Active stabilization of compressor instability and surge in a working engine. ASME J. Turbomachinery, 115(1):68-75, January 1993.

[27] J.E. Ffowcs Williams and X.Y. Huang. Active stabilization of compressor surge. J. Fluid Mechanics, 204:245-262, July 1989.

[28] D.A. Fink. Surge dynamics and unsteady flow phenomena in centrifugal compressors. Technical Report No. 193, MIT Gas Turbine Laboratory, Cambridge, MA, 1988.

[29] D.A. Fink, N.A. Cumpsty, and E.M. Greitzer. Surge dynamics in a free-spool centrifugal compressor. ASME J. Turbomachinery, 114(2):321-332, April 1992.

[30] Jan Tommy Gravdahl and Olav Englund. Compressor surge control using a close-coupled valve and backstepping. Submitted to the 1997 American Control Conference, 1996.

[31] E.M. Greitzer. Surge and rotating stall in axial flow compressors. Part I: Theoretical compression system model. ASME J. Engineering for Power, 98(2):191-198, April 1976.

[32] E.M. Greitzer. Surge and rotating stall in axial flow compressors. Part II: Experimental results and comparison with theory. ASME J. Engineering for Power, 98(2):199-217, April 1976.

[33] E.M. Greitzer. Review - Axial compression stall phenomena. ASME J. Fluids Engineering, 102(2):134-151, June 1980.

[34] E.M. Greitzer. The stability of pumping systems - The 1980 Freeman scholar lecture. ASME J. Fluids Dynamics, 103(2):193-242, June 1981. 
[35] E.M. Greitzer and F.K. Moore. A theory of post-stall transients in axial compression systems: Part II - Application. ASME J. Engineering for Gas Turbines and Power, 108:231-239, April 1986 .

[36] Guoxiang Gu, Siva Banda, and Andy Sparks. An overview of rotating stall and surge control for axial flow compressors. In Proc. of the 35th IEEE Conference on Decision and Control, volume 5, pages 2786-2791, Kobe, Japan, December 1996.

[37] D.L. Gysling, D.J. Dugundji, E.M. Greitzer, and A.H. Epstein. Dynamic control of centrifugal compressor surge using tailored structures. ASME J. Turbomachinery, 113(4):710-722, October 1991.

[38] D.L. Gysling and E.M. Greitzer. Dynamic control of rotating stall in axial flow compressors using aeromechanical feedback. ASME J. Turbomachinery, 117(3):307-319, July 1995.

[39] M.V. Haak, J.-E. van Krimpen, and H.J. Wormgoor. Optimization of a centrifugal compressor stage performance by utilizing the latest aerodynamic technology. In Proc. of the 6th European congress on fluid machinery for the oil, petrochemical and related industries, volume C508/020/96, The Hague, The Netherlands, June 1996.

[40] K.E. Hansen, P. Jørgensen, and P.S. Larsen. Experimental and theoretical study of surge in a small centrifugal compressor. ASME J. Fluids Engineering, 103(3):391-395, September 1981.

[41] J.M. Haynes, G.J. Hendricks, and A.H. Epstein. Active stabilization of rotating stall in a threestage axial compressor. ASME J. Turbomachinery, 116(2):226-239, April 1994.

[42] G.J. Hendricks and D.L. Gysling. Theoretical study of sensor-actuator schemes for rotating stall control. J. Propulsion and Power, 10(1):101-109, February 1994.

[43] R. Hunziker and G. Gyarmathy. The operational stability of a centrifugal compressor and its dependence on the characteristics of the subcomponents. ASME J. Turbomachinery, 116(2):250259, April 1994.

[44] Bram de Jager. Rotating stall and surge control: a survey. In Proc. of the 34th IEEE Conference on Decision and Control, volume 2, pages 1857-1862, New Orleans, LA, December 1995.

[45] M. Krstić, J.M. Protz, J.D. Paduano, and P.V. Kokotović. Backstepping designs for jet engine stall and surge control. In Proc. of the 34th IEEE Conference on Decision and Control, volume 3, pages 3049-3055, December 1995

[46] Pijush K. Kundu. Fluid mechanics. Academic Press Inc., London, 1990.

[47] Der-Cheng Liaw and Eyad H. Abed. Stability analysis and control of rotating stall. In Proc. NOLCOS '92, pages 88-93, Bordeaux, France, June 1992. IFAC.

[48] J.P. Longley. A review of nonsteady flow models for compressor stability. ASME J. Turbomachinery, 116(2):202-215, April 1994.

[49] F.K. Moore. A theory of rotating stall of multistage axial compressors: Part I, II and III. ASME J. Engineering for Gas Turbines and Power, 106(2):313-336, April 1984.

[50] F.K. Moore and E.M. Greitzer. A theory of post-stall transients in axial compression systems: Part I - Development of equations. ASME J.Engineering for Gas Turbines and Power, 108(1):6878, January 1986.

[51] Bruce R. Munson, Donald F. Young, and Theodore H. Okiishi. Fundamentals of fluid mechanics. John Wiley \& Sons, Inc., 1994.

[52] H. Nijmeijer and A.J. van der Schaft. Nonlinear dynamical control systems. Springer, New York, 1990.

[53] A. Eli Nisenfeld. Centrifugal compressors. Instrument Society of America, 1982. 
[54] Johan van den Oever. Literature study on surge and rotating stall. Technical Report WOC-WET 96.018, Fac. of Mechanical Engineering, Eindhoven University of Technology, March 1996.

[55] J.D. Paduano, L.Valavani, A.H. Epstein, E.M. Greitzer, and G.R. Guenette. Modeling for control of rotating stall. Automatica, 30(9):1357-1373, September 1994.

[56] J.E. Pinsley, G.R. Guenette, A.H. Epstein, and E.M. Greitzer. Active stabilization of centrifugal compressor surge. ASME J. Turbomachinery, 113(4):723-732, October 1991.

[57] J.S. Simon and L. Valavani. A Lyapunov based nonlinear control scheme for stabilizing a basic compression system using a close-coupled valve. In Proc. of the 1991 American Control Conference, volume 3, pages 2398-2406, Boston, MA, 1991.

[58] J.S. Simon, L. Valavani, A.H. Epstein, and E.M Greitzer. Evaluation of approaches to active compressor surge stabilization. ASME J. Turbomachinery, 115(1):57-67, January 1993.

[59] J.-J.E. Slotine and Weiping Li. Applied nonlinear control. Prentice Hall, 1991.

[60] A.H. Stenning. Rotating stall and surge. ASME J. Fluids Engineering, 102:14-20, March 1980.

[61] George Stephanopoulos. Chemical process control: an intoduction to theory and practice. Prentice Hall, 1984.

[62] J.M.T. Thompson and H.B. Stewart. Nonlinear dynamics and chaos. John Wiley \& Sons Ltd., 1986.

[63] K. Toyama, P.W. Rundstadler, and R.C. Dean. An experimental study of surge in centrifugal compressors. ASME J. Fluids Engineering, 99(1):115-131, 1977.

[64] Marc van de Wal and Frank Willems. Selection of actuators and sensors for compressor control. Technical Report WFW 96.155, Fac. of Mechanical Engineering, Eindhoven University of Technology, December 1996.

[65] H.O. Wang, R.A. Adomaitis, and E.H. Abed. Nonlinear analysis and control of rotating stall in axial flow compressors. In Proc. of the 1994 American Control Conference, pages 2317-2321, Baltimore, MD, June 1994.

[66] A.M. Wo and J.P. Bons. Flow physics leading to system instability in a centrifugal pump. ASME J. Turbomachinery, 116(4):612-620, October 1994. 